\title{
Desenvolvimento humano municipal no Estado da Bahia
}

\author{
Nadja Simone Menezes Nery de Oliveira \\ Universidad del Valle (UNIVALLE) \\ Jandir Ferrera de Lima \\ Universidade Estadual do Oeste do Paraná (UNIOESTE) \\ Roselaine Navarro Barrinha \\ Universidade Estadual do Oeste do Paraná (UNIOESTE)
}

Recebido: 25/04/2018 Versão revisada (entregue): 05/04/2019 Aprovado: 24/05/2019

\begin{abstract}
Resumo
Este artigo examina o Índice de Desenvolvimento Humano Municipal (IDHM) dos municípios do Estado da Bahia, conforme metodologia do Programa das Nações Unidas para o Desenvolvimento. $\mathrm{O}$ estudo se baseia em dois tipos de análise do desenvolvimento municipal das microrregiões da Bahia, referentes aos anos 2000 e 2010: a Bahia em comparação à média brasileira do IDHM; e, os municípios baianos em relação à média da região Nordeste do IDHM. Os resultados revelaram, por um lado, que a maior parte dos municípios que estavam no círculo vicioso da pobreza permaneceu nesta condição e/ou teve sua participação ligeiramente reduzida no período analisado; por outro lado, aumentou o número dos municípios classificados como tendendo ao desenvolvimento. $O$ padrão de desenvolvimento no Estado da Bahia foi caracterizado por ganhos substantivos em termos de indicadores sociais, enquanto os ganhos em termos de crescimento econômico foram inferiores em relação à média nacional.
\end{abstract}

Palavras-chave | Bahia; desenvolvimento humano; desenvolvimento regional; IDHM; subdesenvolvimento.

Código JEL | O15 I32 F53

\section{Municipal human development in Bahia (Brazil)}

\begin{abstract}
This paper analyzes the Municipal Development Index (IDHM) of the municipalities in Bahia, according to methodology of the United Nations Development Program (UNDP). The study carries out two types of analysis on the municipal development in Bahia's micro-regions in 2000 and 2010: for the municipalities of Bahia compared to the Brazilian average of the IDHM; And for the municipalities of Bahia in relation to the average of the Northeast region, in the performance of the IDHM. The results revealed that most of the municipalities that were in the vicious circle of poverty in 2000 remained in this condition and/or had their participation slightly reduced in the period analyzed. On the other hand, the number of municipalities
\end{abstract}


classified as tending to development increased. The pattern of development in Bahia was characterized by substantial gains in terms of social indicators, while gains in terms of economic growth were lower than the national average.

Keywords | Bahia; human development; Municipal Human Development Index; regional development; underdevelopment.

JEL-Code | O15 I32 F53

\section{Desarrollo humano municipal en el Estado de Bahia}

\section{Resumen}

Este artículo analiza el Índice de Desarrollo Humano Municipal (IDHM) de los municipios del Estado de Bahia, conforme metodología del Programa de las Naciones Unidas para el Desarrollo. El estudio realiza dos tipos de análisis del desarrollo municipal de las microrregiones de Bahia referente a los años 2000 y 2010: análisis de Bahia en comparación con la media brasileña del IDHM; y para los municipios bahianos en relación a la media de la región Nordeste del IDHM. Los resultados revelaron, por un lado, que la mayor parte de los municipios que estaban en el círculo vicioso de la pobreza permanecieron en esta condición y / o tuvieron su participación ligeramente reducida en el período analizado; por otro lado, aumentó el número de los municipios clasificados como tendiendo al desarrollo. El patrón de desarrollo en el Estado de Bahia fue caracterizado por logros sustantivos en términos de indicadores sociales, mientras que los logros en términos de crecimiento económico fueron inferiores en relación al promedio nacional.

Palabras-clave | Bahía; desarrollo humano; desarrollo regional; IDHM; subdesarrollo.

Código JEL | O15 I32 F53

\section{Introdução}

No Brasil, as disparidades de renda e a pobreza têm raízes históricas, pois coexistem desde a colonização e se agravaram ao longo do tempo. Tais disparidades ocorrem tanto do ponto de vista regional, em que se tem o Nordeste como a região com os piores indicadores de pobreza e desenvolvimento, quanto intrarregionalmente. Os indicadores de desenvolvimento humano da Região Nordeste do Brasil, em sua maioria, apresentam valores de baixo desenvolvimento, revelando não só desigualdades interregionais como também intrarregionalmente. A presença das disparidades intrarregionais de desenvolvimento humano aponta para a necessária construção/aplicação de políticas regionais de inclusão social que atuem para além da esfera interregional, ou seja, também no âmbito intrarregional. 
Para que sejam formuladas políticas públicas capazes de promover uma reversão do quadro de desigualdades existente é preciso identificar os fatores que afetam o crescimento e o desenvolvimento socioeconômico. No caso da Bahia, assim como em todo o Nordeste brasileiro, o processo histórico de formação econômica e de desenvolvimento é marcado por desigualdades sociais e regionais e caracterizado pela concentração de desenvolvimento, de renda e de capital. Assim, pode-se afirmar que as desigualdades sociais e regionais entre os municípios baianos advém da própria formação econômica da Bahia e de seus municípios, tendo sido fundamentada na grande propriedade, na força de trabalho escrava e, sobretudo, no modelo voltado para o mercado externo.

Neste contexto, este artigo analisa o Índice de Desenvolvimento Humano Municipal (IDHM), estimado pelo Programa das Nações Unidas para o Desenvolvimento (PNUD), dos municípios baianos para os anos de 2000 e 2010. O estudo realiza dois tipos de análise do desenvolvimento municipal regional: os municípios da Bahia em comparação à média brasileira do IDHM, e os municípios baianos em relação à média nordestina no desempenho do IDHM. Deste modo, o estudo busca proporcionar um melhor entendimento acerca do desenvolvimento socioeconômico do estado da Bahia e, assim, servir como suporte para possíveis políticas governamentais.

O presente estudo, além de fazer uma análise descritiva dos resultados do IDHM a partir de dados secundários dos municípios baianos, também aborda o círculo vicioso da pobreza, isto é, a persistência de baixos indicadores humanos em alguns municípios do estado da Bahia. Vale destacar que este estudo não se aprofunda quanto aos elementos e/ou fatores que conduziram aos valores apresentados pelo IDHM no período analisado. Em outros termos, a preocupação é apenas identificá-los na medida em que se acredita que eles exerçam alguma influência para que o município, ao longo do tempo, insira-se ou permaneça no círculo vicioso do subdesenvolvimento.

Além desta introdução, o presente estudo divide-se em mais quatro seções. $\mathrm{Na}$ primeira, são discutidos os aspectos conceituais do Índice de Desenvolvimento Humano, sua estimativa e composição. A segunda seção trata da conceitução do círculo vicioso da pobreza, na medida em que ela por si é uma negação do desenvolvimento humano. A seção três se dedica à evidenciar a metodologia utilizada. Na seção quatro são feitas as análises sobre os resultados do Indicador de Desenvolvimento Municipal para a Bahia, a comparação da média interregional (média do IDHM dos municípios baianos versus a média do Brasil) e intrarregional (média do IDHM dos municípios baianos versus a média da região Nordeste). As considerações finais sumarizam este estudo. 


\section{Desenvolvimento humano}

O tema desenvolvimento econômico faz-se presente nos mais distintos espaços instituicionais e geográficos. Certamente, o ambiente acadêmico e os que direta ou indiretamente se relacionam com as instâncias de governança estatal ocupam papel importante na referida discussão que, por sua vez, é extrapolada para a população em geral por meio dos meios de comunicação diversos. O fato é que, apesar da presença marcante do referido tema no âmbito social doméstico ou internacional, a compreensão sobre o significado do conceito de desenvolvimento econômico e, portanto, dos caminhos para se atingí-lo são uma presença marcante (SACHS, 2008).

É justamente em face desta verificação que é preciso retomar pelo ponto de vista histórico o desenrolar das discussões a respeito do conceito de desenvolvimento econômico, preocupação estas que vem sendo abraçada por diversos pesquisadores contemporâneos, que procuram estabelecer as bases empíricas sobre as mais diversas teorias do crescimento e do desenvolvimento econômico se fundamentaram. Em tal esforço de investigação, uma das evidências têm sido, inclusive, a de que as raízes de tais teorias podem ser encontradas "[...] na filosofia da Grécia Antiga, nas práticas e políticas vigentes na República e no Império Romano e nas influências exercidas pela Igreja na sociedade medieval" (SIEDENBERG, 2013, p. 33), assim como no momento de transição desta para a moderna.

Uma discussão mais destalhada da evolução histórica do conceito em questão permitiria precisá-lo um pouco mais, assim como o caminho estabelecido a partir das mais distintas teorias do desenvolvimento econômico no sentido de alcançálo. São tais teorias, diga-se de passagem, que conformam a discussão acadêmica e exercem (em maior ou menor grau) influência sobre as práticas e políticas adotadas com vistas a se atingí-lo. Apesar da importância de tal detalhamento, o que se objetiva neste espaço é promover uma descrição mais geral das mudanças sofridas sobre o conceito de desenvolvimento econômico.

No sentido do exposto, é preciso ressaltar que a preocupação com tal significância aparece na intensificação do debates e das críticas que marcam o período posterior à Segunda Guerra Mundial. É no referido período que as consequências oriundas do conflito (econômicas e políticas) passam a demandar tanto no âmbito da Europa quanto no da periferia capitalista, modificações no sentido de se pensar o processo de desenvolvimento econômico. (SACHS, 2008; HOBSBAWM, 2013). Nas instâncias acadêmicas e políticas, tomou-se por aceitável a importância do Estado de bem-estar social e, portanto, do planejamento como condições necessárias na condução do processo de crescimento e desenvolvimento econômico (HOBSBAWM, 2013).

A ampliação do debate acerca do desenvolvimento econômico à época resultaram 
em estudos que defendiam uma percepção quanto ao referido termo, fosse além do significado de representado pelo crescimento econômico, ou seja, de algo que trouxesse além do aumento da renda, uma distribuição mais adequada da mesma, implicando assim em melhorias no aspecto social

Apesar da positividade representada pela ampliação do debate e da inserção dos aspectos político e social, ainda predominava (o que se estendeu, notadamente nas regiões periféricas até meados dos anos 1970) a percepção do desenvolvimento econômicco enquanto algo associado ao crescimento econômico, à industrialização, à reprodução do modo de vida ocidental, notadamente o vigente nas economias ocidentais de maior desenvolvimento. Predominava, ainda, a concepção de que do crescimento decorreria o desenvolvimento econômico. O referido evidencia-se no próprio discurso do presidente Truman, datado de 20 de janeiro de 1949, em que anunciou um pacote de ajuda técnica para os países subdesenvolvidos da África, da Ásia e da América Latina (HOBSBAWM, 2013).

A signficância do termo desenvolvimento econômico expressada no discurso do presidente norte-americano pode ser vista nas pesquisas acadêmicas desenvolvidas por e a partir da obra de Rostow (1974), notadamente em "As etapas do desenvolvimento econômico: um manifesto não comunista", de meados dos anos 1950. É importante ressaltar que, apesar das inúmeras críticas que tal obra recebeu, a associação entre desenvolvimento econômico com o modelo ocidental, pautado na industrialização e na ampliação do consumo, seguiu presente nos países da periferia capitalista (RODRIK, 2014). Daí que, desde os anos 1950, os países da periferia capitalista, notadamente os latino-americanos, tenham se lançado no setindo de fazer avançar a sua industrialização, pautando esta num elevado nível de endividamento externo.

O entendimento de que a progressiva acumulação de capital seria suficiente para assegurar condições adequadas de existência à população, na medida em que do crescimento econômico decorreria naturalmente melhorias em termos sociais e políticos, esvaziou, de certa forma, a adoção de práticas e de políticas (como no caso do Brasil) que levassem em consideração outros fatores, como bem-estar, diminuição da desigualdade, da pobreza etc. $\mathrm{O}$ referido se refletiu, portanto, na adoção de práticas e de políticas notadamente de ordem econômica, que privilegiaram o crescimento econômico, enquanto políticas de cunho social, de enfrentamento da desigualdade e de combate à pobreza foram deixadas de lado. Foi tal percepção do processo de desenvolvimento econômico, enquanto derivada naturalmente do crescimento econômico, que serviu de base para justificar a postura do Estado notadamente nos anos do governo militar (GREMAUD; DE VASCONCELOS; TONETO JÚNIOR., 2016).

No entanto, a referida concepção quanto ao processo de desenvolvimento econômico tinha por foco a análise do desenvolvimento econômico a partir dos países considerados desenvolvidos. Esses países se caracterizavam por elevado 
nível de produção industrial e de desenvolvimento tecnológico. Deixou de se considerar, ou se deu pouca importância, ao fato de que os países periféricos conduziriam o seu processo de industrialização a partir de uma condição de inegável atraso econômico, social e, mesmo, político. Em outros termos, eles encaminhariam um processo de industrialização dirigido (inclusive, pode se dizer que certa forma de fora para dentro) e num momento em que sua condição representava a experimentada pelos países desenvolvidos no passado, relacionando-se comercial, política e financeiramente com estes no presente. A disparidade era, portanto, inegável, e inevitavelmente traria impactos (GREMAUD, VASCONCELOS, TONETO JR., 2016; HOBSBAWM, 2013).

Dado o exposto, é possível ao menos de forma tangencial compreender os resultados aparentemente discrepantes do processo de desenvolvimento econômico levado adiante com foco quase que exclusivo em políticas econômicas, notadamente, as que privilegiaram a industrialização. Em tais termos, o crescimento do bolo se deu amparado, no caso do Brasil, num enorme endividamento externo e, ainda, marcado por um agravamento da desigualdade social. Em tais termos, foi se evidenciando que o desenvolvimento das nações dependia, portanto, de suas dotações de capital, mas esta - ainda que condição necessária para o desenvolvimento - não seria suficiente. Seria necessário que as mudanças trazidas à tona pelo avanço na produção e na industrialização fossem traduzidos numa melhor distribuição de renda, ou seja, tais avanços deveriam favorecer a redução das desigualdades sociais (FURTADO, 2000; CEPAL, 2014).

Com base no referido, seria possível compreender o fato de que uma região avance economicamente sem que obtenha, ao mesmo tempo, elevação nos níveis de bem-estar da sua população seja por conta da má distribuição da riqueza, seja pela dissociação existente entre os bens materiais e outros 'bens' intangiveis mas igualmente importantes para elevar o bem-estar de uma sociedade, como coesão social, saúde, laços familiares e lazer (NURKSE, 1957; SANT'ANA, 2008).

Melhorias na distribuição de renda e mobilidade entre as classes sociais apesar de serem condições necessárias, não são suficientes para o desenvolvimento humano de uma sociedade, ou seja, devem-se considerar fatores que vão além de questões de ascensão social, recursos monetários e bens disponíveis, dentre os quais, se pode citar o acesso a bens e serviços básicos (públicos ou privados) de qualidade, principalmente os que se refletem nos indicadores sociais e se referem à qualidade e manutenção da vida das pessoas (MYRDAL, 1977; SEN, 2001; 2010; RAIHER; FERRERA DE LIMA, 2014).

Desse modo, desenvolvimento econômico consiste em crescimento (incrementos positivos no produto e na renda) transformado para satisfazer as mais diversas necessidades do ser humano, como saúde, educação, alimentação, habitação, transporte, lazer, dentre outras (DE OLIVEIRA, 2002; CAMPOS, 2014). Nesse sentido, um dos autores contemporâneos de expressiva importância na discussão 
sobre a temática do desenvolvimento econômico reforça, junto com outros que integram a corrente teórica Liberal Social que modificações, tanto quantitativas quanto qualitativas, devem ser vistas como reflexos do desenvolvimento econômico de uma sociedade. $\mathrm{O}$ desenvolvimento está necessariamente relacionado à elevação do produto, da renda, do grau de investimentos, do montante de empregos, à redução dos abismos sociais, à distribuição de recursos mais equitativa, à melhoria na condição de vida da população e ao progresso tecnológico. Todos esses, por sua vez, levam ao aumento do nível de liberdade da sociedade (SEN, 2000; 2010; RODRIK, 2014).

Sob tal ótica é que a referida corrente teórica volta a enfatizar o papel extremamente relevante do Estado no sentido de atuar, por meio da adoção de práticas e políticas tanto econômica quanto sociais, conferindo aos indivíduos a liberdade $^{1}$ de viabilizar o desenvolvimento de suas potencialidades. A viabilização de arranjos econômico-sociais que conduzam a tal fim seriam responsáveis pelo avanço da sociedade como um todo, ou seja, seria fundamental para que cada nação pudesse de fato avançar rumo a um desenvolvimento mais pleno, que contemplasse, portanto, os mais distintos aspectos (SEN, 2010; CAMPOS, 2014). Novamente, é preciso enfatizar que o crescimento econômico, é um importante instrumento para se reduzir a pobreza, sem embargo, ele não é o único e de fato é possível que ele aconteça em uma dada localidade, sem que nela se observe a ocorrência de melhorias nas condições de vida e bem-estar de sua população. De outra forma, uma região pobre que consiga melhorar seus indicadores de saúde e educação pode impactar positivamente no seu crescimento econômico. É nesse sentido que aparece a importância do papel do Estado enquanto executor de políticas públicas que visem à criação de oportunidades sociais capazes de gerar melhorias nos indicadores de desenvolvimento humano que possam reverter o quadro existente de desigualdades entre as regiões (SOBRINHO, 2001; SEN, 2010). Em outros termos, a participação efetiva do Estado enquanto executor de tais políticas pode ser determinante no sentido de conduzir um processo que de fato vá para além do crescimento econômico. Ou seja, a situação de pobreza, e, consequentemente, do subdesenvolvimento econômico, pode ser revertida com investimentos em infraestrutura, saúde e educação, principalmente neste último componente, uma vez que este é entendido como investimento em estoque de capital humano. O capital humano contribui tanto para o crescimento econômico quanto para o desenvolvimento econômico na medida em que sua ampliação tem uma relação direta com a renda, com o nível de produtividade da mão de obra e

\footnotetext{
${ }^{1}$ Como liberdade deve-se entender aquela baseada na abordagem das capacitações do economista indiano Amartya Sen tal abordagem está fundamentada basicamente em mensurar o bem-estar dos indivíduos de acordo com a liberdade que esses possuem em ter ou fazer aquilo que almejem com base no princípio da justiça. Busca-se avaliar a liberdade de escolha individual que está fortemente relacionada à qualidade de vida. Desse modo, tem-se a possibilidade de capturar características relevantes como heterogeneidades pessoais, diversidades ambientais, variabilidades no clima social, diferenças de perspectivas relativas e distribuições intrafamiliar.
} 
com a melhoria na qualidade de vida de uma sociedade (SCHULTZ, 1987; MILANOVIC, 2015).

Sendo assim, o papel do Estado é importante na reversão do quadro de subdesenvolvimento, que se forma, se impõe desde o âmbito institucional, na medida em que a não neutralidade neste presente, determina os rumos a serem percorridos no processo de desenvolvimento econômico, como na ação direta nas regiões por meio de investimentos e de políticas públicas diferenciadas, atuando no incentivo à criação de indústrias, provocando melhorias na produção agropecuária, no fortalecimento de redes de inovação e fomento às externalidades positivas regionais (LIMA, 2012).

O debate sobre o tema do desenvolvimento humano vem ocupando lugar de destaque na sociedade contemporânea. A importância de tal temática vem exigindo uma discussão ampliada a respeito do significado em si do desenvolvimento econômico, bem como a elaboração de índices capazes de traduzi-lo efetivamente. Nesses dois aspectos, é importante enfatizar principalmente o papel que o Programa das Nações Unidas para o Desenvolvimento (PNUD) vem desempenhando, tanto no que se refere à ampliação do conceito de desenvolvimento humano quanto na forma da sua mensuração - como se pode verificar a partir da elaboração do Índice de Desenvolvimento Humano (IDH). O IDH é uma medida resumida do progresso de longo prazo no qual é possível fazer comparações entre regiões e se divide em três dimensões básicas do desenvolvimento humano: renda, saúde e educação (PNUD, 2014). Tal instrumento, é importante mencionar, evidencia os avanços/retrocessos das práticas adotadas pelo Estado, nas suas mais distintas instâncias, no sentido de levar adiante o desenvolvimento econômico entendido de forma mais ampla, ou seja, enquanto processo capaz de permitir que tanto o indivíduo quanto a sociedade desenvolvam as potencialidades que lhe são imanentes.

É nesse contexto que a ampliação dos estudos voltados às dimensões do desenvolvimento humano, ao evidenciarem, por meio de instrumentos como o IDH, um retrato mais acurado das distintas realidades territoriais que compõem a nação, são fundamentais para evidenciar as problemáticas dimensionais presentes em cada espaço. Isso proporciona a recomendação de novas formas de gestão pública municipal, assim como em suas organizações incorporadas nesse processo (BATALHÃO et al., 2018).

É, portanto, nesse sentido, que a análise do IDH e dos seus subíndices contribui diretamente para a reversão dos processos de subdesenvolvimento. Para que tais processos sejam revertidos, é de fundamental importância a criação e aplicação de políticas públicas de combate ao subdesenvolvimento e à pobreza. Em tal processo, é cada vez mais importante o papel do Estado na criação e execução de 
políticas públicas que visem a melhoria dos indicadores socioeconômicos da população no sentido de mitigar as desigualdades econômicas e sociais.

\section{Círculo vicioso da pobreza e causação circular cumulativa}

A Segunda Guerra Mundial fez surgir uma nova forma de nacionalismo, na qual as nações menos desenvolvidas passaram a reivindicar, além da liberdade, a igualdade de oportunidades, almejando, por conseguinte, a obtenção do desenvolvimento econômico. Assim, a perspectiva aqui presente é a de que a igualdade de oportunidades entre os indivíduos de uma sociedade é um dos principais caminhos para se alcançar melhorias nos indicadores de capital humano.

Nesse sentido, é importante trazer à tona o conceito de círculo vicioso da pobreza e causação circular cumulativa. Esse deduz que, quanto mais se conhece a forma como os fatores econômicos e não econômicos se inter-relacionam, maiores são as chances de se alcançar bons resultados em termos de políticas, principalmente as voltadas à alteração da configuração social. Dado o mencionado, a causação circular cumulativa pode ter efeitos tanto negativos quanto positivos. Uma situação de pobreza e exclusão social se reforça cumulativamente, isto é, 'a pobreza se torna a sua própria causa'. O mesmo reforço ocorre para uma situação de bonança e vida plena (MYRDAL, 1968; RAIHER; FERRERA DE LIMA, 2014; OLIVEIRA; FERRERA DE LIMA; RAIHER, 2017).

As mais importantes relações circulares que reforçam o círculo vicioso da pobreza são exatamente aquelas que impedem a formação de capital nos países economicamente atrasados, tanto no que se refere ao lado da oferta como da demanda de capital. No entanto, a oferta de capital está relacionada com a propensão a poupar, e a demanda por capital é determinada pela eficiência dos investimentos. Assim, o principal problema do subdesenvolvimento consiste fundamentalmente na dificuldade dos países em formarem capital. Ou seja, é o círculo vicioso da pobreza um dos principais entraves que condicionam a procura de capital e seu uso no processo produtivo (NURKSE, 1957).

Para sair do círculo vicioso da pobreza, ou seja, para que um país saia do estado de subdesenvolvimento, Nurkse (1957) sugere o crescimento equilibrado. Neste sentido, chama a atenção para a importância nesses países da atuação do empresário inovador, pois considera que a dinâmica dos mercados internos nos países subdesenvolvidos é ditada pelas inovações tecnológicas por parte dos empresários, o que acaba gerando o surgimento de novos mercados. Deste modo, o crescimento equilibrado, posto como saída do círculo vicioso da pobreza é incentivado pelo aumento do mercado interno em conjunto com os investimentos neste. O equilíbrio estacionário do subdesenvolvimento é rompido na medida em que o investimento vai sendo aplicado em diferentes ramos produtivos, o que 
acaba levando à expansão do mercado total e do emprego, e, com isso, os indivíduos vão auferir mais renda, o que contribui para a superação da pobreza no seu caráter unidimensional.

Incentivos no que diz respeito à poupança doméstica, sejam via políticas fiscais, monetárias ou por meio de restrições de importações de bens de consumo, isto é, a propensão a poupar e o papel assumido pelas finanças são fundamentais para a formação de capital nos países subdesenvolvidos. Então, faz-se necessário uma ação coletiva por meio das finanças públicas para que se rompa o círculo vicioso da pobreza (NURKSE,1957).

Ao contrário de Nurkse (1957), com o princípio da causação circular cumulativa Myrdal (1997) buscava analisar as relações estabelecidas entre espaços desequilibradamente desenvolvidos, os quais acarretariam crescentes agravamentos nas disparidades em termos de desenvolvimento dos países, ou seja, a causação circular cumulativa buscava explicar o porquê de determinadas regiões serem desenvolvidas e outras não e dessa forma entender os condicionantes do subdesenvolvimentos de determinadas e regiões bem como as medidas que deveriam ser tomadas para superar dito subdesenvolvimento.

Myrdal (1997) considerava inadequado o emprego da noção de equilíbrio geral para explicar as mudanças ocorridas no sistema social. Por trás da noção de equilíbrio estável estaria a ideia de que, em resposta a uma mudança em determinada direção, surgiriam, automaticamente mudanças secundárias em direção oposta à primeira, de modo a neutralizá-la. Uma tendência automática em relação à estabilização do sistema social não poderia ser verificada, em vez disso, haveria uma tendência de distanciamento do estado de equilíbrio, o qual seria explicado pelo processo de causação circular cumulativa. Uma vez que este processo cumulativo nutrido pela causação circular não fosse controlado, geraria desigualdades crescentes. É sob essa lógica que o problema dos países subdesenvolvidos reside em efeitos propulsores fracos que, deixados às livres forças do mercado, originam ou a aumentam as desigualdades regionais, que promovem obstáculos ao progresso nestes.

Destarte, segundo o princípio da causação circular cumulativa, uma determinada região, a partir de um efeito propulsor pode se tornar desenvolvida e esse efeito positivo pode promover aumento nos investimentos para a localidade, tornando-a um polo de desenvolvimento. No entanto, tal efeito pode dar-se de forma negativa causando regressão, acentuando ainda mais o caráter de subdesenvolvimento de determinadas regiões. Tal situação acontece porque regiões prósperas tendem a atrair cada vez mais desenvolvimento originado de investimentos oriundos de regiões mais pobres. $O$ processo de causação circular cumulativa da pobreza e das doenças amplia as desigualdades entre países prósperos e países pobres, e ocasiona disparidade entre os níveis de desenvolvimento entre esses países (MYRDAL, 1968; 1970; 1997). 
Nesse contexto, baixos níveis de mobilidade social e educação, por exemplo, são algumas das causas das desigualdades socioeconômicas que se observam em uma sociedade, pois intensificam as desigualdades regionais internas e internacionais, causando a diminuição dos salários e a produtividade dos indivíduos. Dificultando, assim, a melhoria na qualidade de vida dos membros de uma sociedade, perpetuando e acirrando as desigualdades internas e externas (MYRDAL, 1968; 1970).

É partindo de tal lógica que a teoria do capital humano argumenta que a educação torna as pessoas mais produtivas, elevam seus salários e tem forte influência sobre o crescimento econômico de uma região. A educação, mensurada por meio do nível de qualificação de uma população, contribui para reduzir as diferenças econômicas e fortalecer as economias regionais. Uma força de trabalho instruída, com qualidade de vida, acesso aos serviços sociais básicos e cidadania plena terá mais produtividade e eficácia em suas atividades. Regiões nas quais os investimentos em educação, saúde e acesso à alimentação são mais elevados em relação às demais tendem a auferir maiores ganhos de produtividade. Então, investir em capital humano é uma importante medida para se reduzir as desigualdades econômico-regionais. Esses investimentos geram, no longo prazo, bem-estar social tanto para o detentor da força de trabalho quanto para a sociedade como um todo. Neste contexto, o Estado exerce um papel de vital importância ao priorizar a criação de escolas e universidades destinadas à preparação de capital humano, ação essencial para o desenvolvimento econômico e rompimento do círculo vicioso da pobreza (VIANA; FERRERA DE LIMA, 2010; MYRDAL, 1968).

\section{Metodologia}

Este estudo segue o procedimento metodológico utilizado em outros dois. O primeiro foi o Informe sobre Desarrollo Humano (2002), no qual foram identificados os perfis de desenvolvimento das entidades federativas do México. O segundo, refere-se à análise de Raiher e Ferrera de Lima (2014) para a Região Sul do Brasil. Em ambos os estudos foi utilizada como parâmetro a média obtida por cada dimensão do IDH pelo país, tornando possível observar a presença (ou ausência) de fortalecimento mútuo entre crescimento econômico e desenvolvimento humano, ou uma tendência ao desenvolvimento humano ou crescimento econômico.

Conforme essa metodologia, se um espaço federativo apresentou o indicador de longevidade e educação maior do que a média nacional, juntamente com o indicador de PIB per capita, considerou-se que a mesma entidade encontrava-se em um círculo virtuoso de desenvolvimento, pois consegue aliar ganhos sociais com melhorias econômicas. Se, por outro lado, os indicadores dessas três dimensões 
estivessem abaixo da média nacional, ela estaria em um círculo vicioso. Se o valor da média dos indicadores de longevidade e educação superasse o valor médio nacional, mas não o indicador do PIB per capita, haveria uma tendência ao desenvolvimento na região. No entanto, se situação inversa ocorresse, isto é, o indicador de renda estivesse acima da média nacional, e os indicadores de longevidade e educação abaixo da média, a região estaria apresentando uma tendência ao crescimento.

Os dados utilizados no presente estudo foram extraídos do Atlas do Desenvolvimento Humano no Brasil 2013, realizada pelo Programa das Nações Unidas para o Desenvolvimento (PNUD). Com tais dados, realizou-se um recorte espacial do estado da Bahia para os anos de 2000 e 2010, totalizando 417 municípios/observações para cada dimensão (IDHM - global, IDHM- renda, IDHM- longevidade e IDHM- conhecimento) do Índice de Desenvolvimento Humano Municipal (IDHM). Adotando-se a classificação da citada metodologia, os municípios do estado foram hierarquizados em quatro categorias, conforme o Quadro 1.

\section{Quadro 1 - Hierarquização dos municípios da Bahia quanto ao grau de desenvolvimento humano}

\begin{tabular}{|ll|}
\hline Situação do município & IDH- renda maior do que a média \\
\hline Tendência ao crescimento & $\begin{array}{l}\text { IDH- longevidade e IDH- conhecimento maior do } \\
\text { que a média }\end{array}$ \\
\hline Tendência ao desenvolvimento & $\begin{array}{l}\text { IDH- renda, IDH- longevidade e IDH- } \\
\text { conhecimento maior do que a média }\end{array}$ \\
\hline Círculo virtuoso & $\begin{array}{l}\text { IDH- renda, IDH- longevidade e IDH- } \\
\text { conhecimento menor do que a média }\end{array}$ \\
\hline
\end{tabular}

Fonte: Informe sobre Dessarollo Humano (2002); Raiher e Ferrera de Lima (2014), Oliveira, Ferrera de Lima e Raiher (2017).

A hierarquização propõe quatro escalas analíticas para o desenvolvimento humano. Ela reflete o estágio no qual o município se encontra e fornece parâmetros sobre sua mobilidade entre as escalas ao longo do tempo. Ou seja, fornece parâmetros também para a avaliação de políticas públicas ligadas ao desenvolvimento humano municipal e regional (RAIHER; FERRERA DE LIMA, 2014). 


\section{Perfil do desenvolvimento humano nos municípios da Bahia}

Conforme exposto na introdução, este estudo tem como objetivo fazer uma análise descritiva dos resultados do IDHM dos municípios baianos e do círculo vicioso da pobreza, isto é, a persistência de baixos indicadores humanos. Destarte, na presente seção são apresentados os resultados dos perfis de desenvolvimento dos municípios do estado da Bahia para os anos de 2000 e 2010.

$\mathrm{Na}$ Figura 1 são apresentados os perfis de Desenvolvimento Humano Municipal da Bahia em relação à média brasileira nos anos de 2000 e 2010. É possível perceber duas tendências: o modesto aumento de municípios que tendiam ao desenvolvimento (de 0 para 3) e de municípios pertencentes ao círculo virtuoso (de 5 para 12 municípios), perfazendo uma variação absoluta de 300\% e 140\%, respectivamente. Nota-se, também, uma redução da quantidade de municípios com IDH de tendência ao crescimento (de 34 para 22) e pertencentes ao círculo vicioso (de 360 para 349), perfazendo uma variação absoluta de $-35 \%$ e $-3 \%$, respectivamente.

Em relação à média brasileira, os resultados revelaram que os municípios baianos tiveram um padrão de desenvolvimento humano com ganhos reforçados em termos de indicadores sociais (longevidade e educação). No entanto, os ganhos em termos de crescimento econômico foram inferiores às conquistas da média nacional, isto é, houve piora com relação ao PIB per capita na Bahia. Conforme o Informe sobre Desarrollo (2002), o ideal para um indicador de convergência nos índices regionais de desenvolvimento seria a redução nas disparidades que, em média, existe entre os índices das regiões com relação ao índice nacional. Dessa maneira, se a desigualdade entre as regiões reduz constantemente em uma trajetória de desenvolvimento regional convergente com a média nacional. 


\section{Figura 1 - Desenvolvimento Humano dos municípios da Bahia em relação à média brasileira - 2000 e 2010}

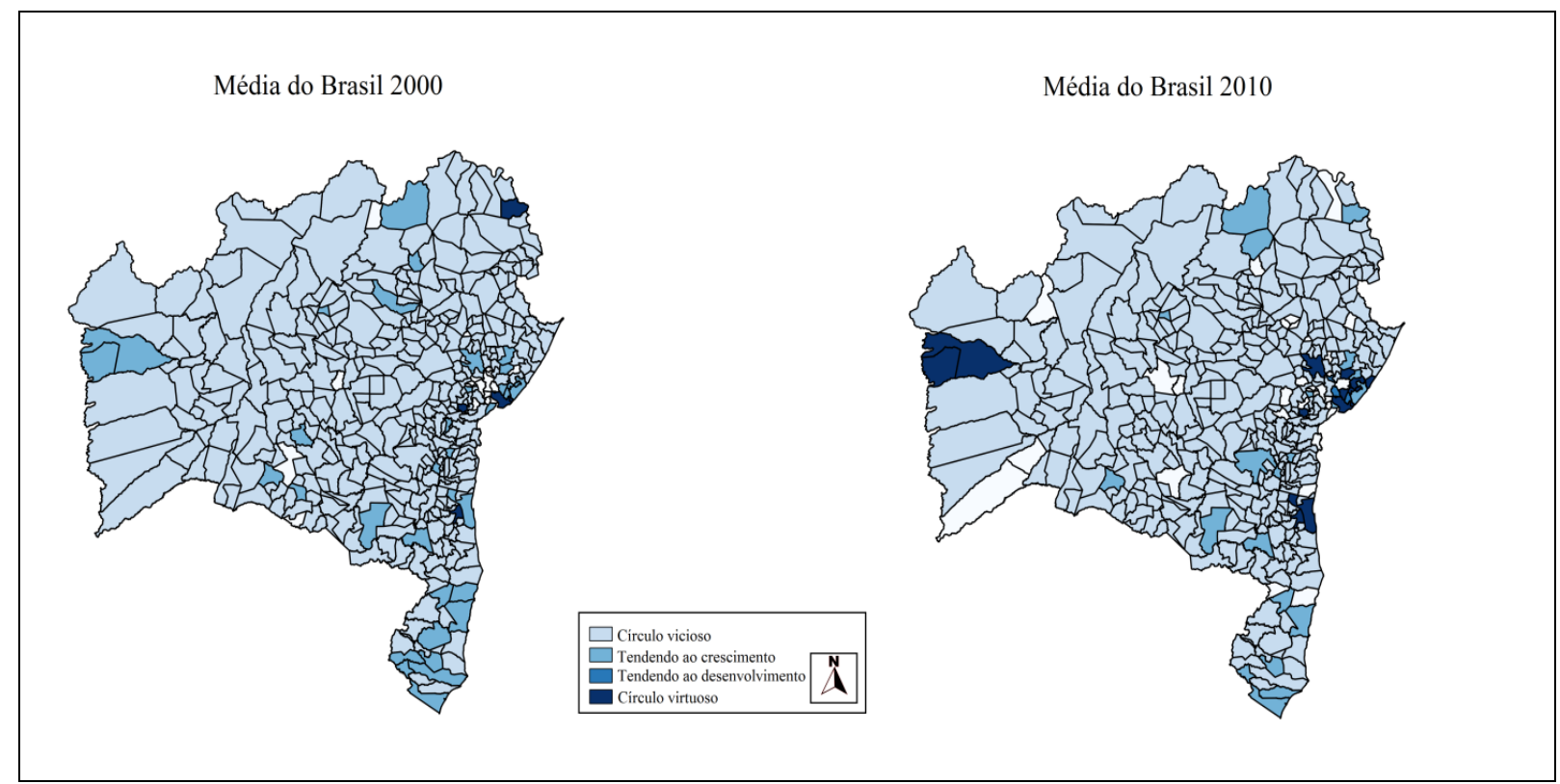

Fonte: Resultados da pesquisa.

Ainda de acordo com a Figura 1, observa-se que, em 2010, o desenvolvimento humano municipal da Bahia migrou para os municípios das mesorregiões Extremo-Oeste baiano (Barreiras e Luís Eduardo Magalhães) e do Sul Baiano (Ilhéus e Itabuna), e consolidou-se na mesorregião Metropolitana de Salvador (Salvador, Candeias, Dias D’Ávila, Mata de São João e Lauro de Freitas). No primeiro caso, tem-se a expansão da fronteira agrícola ${ }^{2}$ e toda importância que o agronegócio vem representando nessa região nos últimos anos.

Entre os anos de 2000 e 2010, quando comparado à média nacional, a Bahia apresentou ganhos nos seus indicadores sociais, ou seja, ocorreram acréscimos nos investimentos em saúde e educação que contribuíram para a melhoria da qualidade de vida e do perfil do capital humano da população baiana. Entretanto, no quesito crescimento econômico também ficou para trás em relação à média do IDHM Brasil.

Na Figura 2 são apresentados os perfis de Desenvolvimento Humano Municipal da Bahia em relação à média na Região Nordeste nos anos de 2000 e 2010. Nela é possível observar duas tendências: aumento no indicador de tendência ao desenvolvimento (de 14 para 21) e redução no montante de municípios que se

\footnotetext{
2 A expansão da fronteira agrícola do Extremo-Oeste baiano se deu nos fins da década 1970, juntamente com a chegada dos migrantes sulistas, vindos principalmente do Rio Grande do Sul. As primeiras cidades do Oeste Baiano que receberam esse fluxo migratório rio-grandense-do-sul, foram Barreiras e Luís Eduardo Magalhães (COSTA; MONDARDO, 2013).
} 
encontram na faixa do círculo vicioso (de 100 para 77), perfazendo uma variação absoluta de $50 \%$ e $-30 \%$, respectivamente. Com relação às outras faixas de desenvolvimento humano, os municípios com o IDH pertencentes à faixa tendendo ao crescimento tiveram uma redução de aproximadamente $-12 \%$ (de 142 para 125), enquanto os municípios classificados na faixa do círculo virtuoso do desenvolvimento humano aumentaram em 6,7\% (de104 para 111).

Figura 2 - Desenvolvimento Humano dos municípios da Bahia em relação à média do Nordeste -2000 e 2010

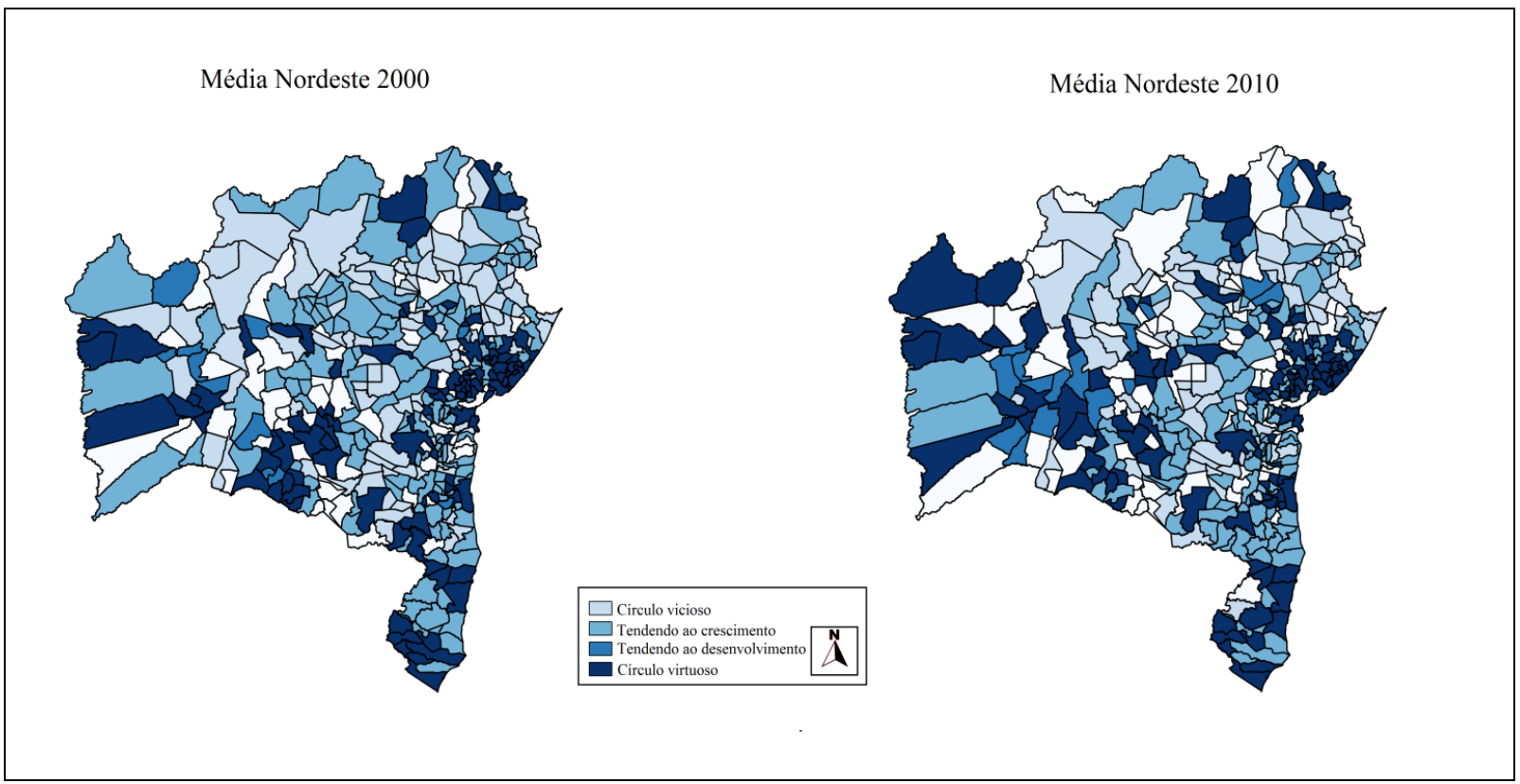

Fonte: Resultados da pesquisa.

Na comparação intrarregional, ou seja, em relação à média da Região Nordeste, esses dados apontam um padrão de desenvolvimento humano com ganhos reforçados em termos de indicadores sociais (longevidade e educação). Situação semelhante da comparação com a média brasileira, diferindo apenas no tamanho da variação do IDHM de 2000 para 2010. No que diz respeito à melhoria do indicador educacional, tal resultado corrobora com os argumentos de Schultz (1987) e Milanovic (2015), de que o capital humano é capaz de contribuir tanto para o crescimento econômico quanto para o desenvolvimento econômico.

Entre os anos de 2000 e 2010, quando comparado à média do Nordeste, mais uma vez se percebe a importância da expansão da fronteira agrícola no desenvolvimento humano municipal da mesorregião do Extremo-Oeste baiano. Também se observa uma estagnação do desenvolvimento dos municípios do semiárido baiano, mais especificamente na mesorregião do Vale São-Franciscano da Bahia. 
Ao se observar as duas figuras, é notória a melhoria nos indicadores sociais, embora esses tenham ficado distantes da média nacional. Portanto, é essencial que os municípios baianos avancem mais do que a média brasileira tanto no âmbito do desenvolvimento humano quanto no comparativo com os demais municípios brasileiros.

A Tabela 2 apresenta o número e o percentual de municípios baianos em cada estágio de desenvolvimento humano com relação à média Brasil e à média do Nordeste nos ano de 2000 e 2010. No ano de 2000, em relação à média brasileira do IDHM, os municípios da Bahia estavam mais concentrados na faixa do círculo vicioso do desenvolvimento humano e de tendência ao crescimento. Traduzindo o referido em números percentuais e inteiros, pode-se dizer que 86,3\% (360) e 8,2\% (34) desses municípios se encontravam sob as referidas situações, respectivamente.

Tabela 2 - Estado da Bahia: número de municípios em cada estágio de desenvolvimento humano - 2000 e 2010 (em \%)

\begin{tabular}{|c|c|c|c|}
\hline Parâmetro & Classificação & Total de municípios & $\%$ \\
\hline \multicolumn{4}{|l|}{ Em 2000} \\
\hline \multirow{4}{*}{ Média Brasil } & Tendendo ao crescimento & 34 & 8,2 \\
\hline & Tendendo ao desenvolvimento & - & - \\
\hline & Círculo vicioso & 360 & 86,3 \\
\hline & Círculo virtuoso & 5 & 1,2 \\
\hline \multirow{4}{*}{ Média Nordeste } & Tendendo ao crescimento & 142 & 34 \\
\hline & Tendendo ao desenvolvimento & 14 & 3,3 \\
\hline & Círculo vicioso & 100 & 24 \\
\hline & Círculo virtuoso & 104 & 25 \\
\hline \multicolumn{4}{|l|}{ Em 2010} \\
\hline \multirow{4}{*}{ Média Brasil } & Tendendo ao crescimento & 22 & 5,3 \\
\hline & Tendendo ao desenvolvimento & 3 & 0,7 \\
\hline & Círculo vicioso & 349 & 83,7 \\
\hline & Círculo virtuoso & 12 & 2,9 \\
\hline \multirow{4}{*}{ Média Nordeste } & Tendendo ao crescimento & 125 & 30 \\
\hline & Tendendo ao desenvolvimento & 21 & 5 \\
\hline & Círculo vicioso & 77 & 18,4 \\
\hline & Círculo virtuoso & 111 & 26,6 \\
\hline
\end{tabular}

Fonte: Resultados da pesquisa.

Em 2010, a proporção de municípios pertencentes ao círculo vicioso reduziu para $83,7 \%$ (349) do total dos municípios baianos. As municipalidades baianas com tendendência ao desenvolvimento passaram a constituir $0,7 \%$ (3) desse total. Houve uma discreta melhoria no percentual de municípios que se encontravam no círculo virtuoso, na medida em que este passou para 2,9\% (12). 
Quando se inicia o processo de desenvolvimento humano, a probabilidade de regressão é menor em decorrência do processo cumulativo, pois são reforçados os elementos necessários para a manuntenção do bem-estar de uma sociedade. Pelo mesmo motivo, o processo cumulativo também pode reforçar os efeitos negativos, pois como se verificou, mais municípios classificados no círculo vicioso sofreram depreciação nos elementos responsáveis pelo bem-estar de suas populações (RAIHER; FERRERA DE LIMA, 2014; OLIVEIRA; FERRERA DE LIMA; RAIHER, 2017).

A discreta diminuição dos municípios no círculo vicioso evidencia a incapacidade em acompanhar o ritmo de desenvolvimento do país como um todo, passando de $86,3 \%$ para $83,7 \%$ dos municípios. Verifica-se, portanto, que para tal intervalo de tempo, a propagação do contágio do desenvolvimento humano ocorreu num ritmo menor na Bahia. No entanto, é importante ressaltar um processo interno existente em prol especialmente dos municípios que se enquadravam no círculo vicioso em 2010. Por mais que tais municípios não tenham conseguido acompanhar o ritmo de desenvolvimento intrarregional e interregional (e, por isso, foram enquadrados nesta classificação), a evolução das dimensoes do IDHM, especialmente do conhecimento, foi mais vigorosa nestes espaços.

A grande questão é por que eles foram enquadrados no círculo vicioso se obtiveram taxas de crescimento, em geral, mais intensas? Por mais que se tenha obtido grandes avanços, possivelmente o nível de desenvolvimento humano, $a$ priori, de boa parte desses municípios era bastante pequeno. Assim, ainda que apresentando um crescimento maior o mesmo não foi suficiente para romper o ć́rculo vicioso do subdesenvolvimento existente. Se o ritmo de crescimento econômico se mantiver ao longo do tempo, os municípios tendem a auferir um melhor desempenho na média do IDHM estimulando a transição do estágio de desenvolvimento humano.

Corroborando com esses argumentos, a Figura 3 mostra a persistência do círculo vicioso dos municípios da Bahia de 2000 para 2010 com relação às médias do Brasil e do Nordeste. Na sua maioria, os municípios que se enquadraram nesta classificação já tinham ex ante um nível de desenvolvimento muito baixo, de tal maneira que, mesmo apresentando uma evolução das dimensões do IDHM maior, não foi suficiente para romper com o círculo vicioso existente, estando aquém do desenvolvimento, particularmente quando o parâmetro considerado é o Brasil.

Quando uma região possui elementos negativos arraigados, agravam-se temporalmente as condições de subdesenvolvimento humano. Por isso, é preciso romper com tal círculo vicioso, sendo necessário conhecer os fatores que fomentam a probabilidade de um município permanecer nesta condição. Da mesma forma, somente identificando tais fatores torna-se possível fomentar políticas públicas eficazes capazes de auxiliar no rompimento de tal círculo. 
Figura 3 - Bahia: municípios que permaneceram no círculo vicioso - 2000 para 2010

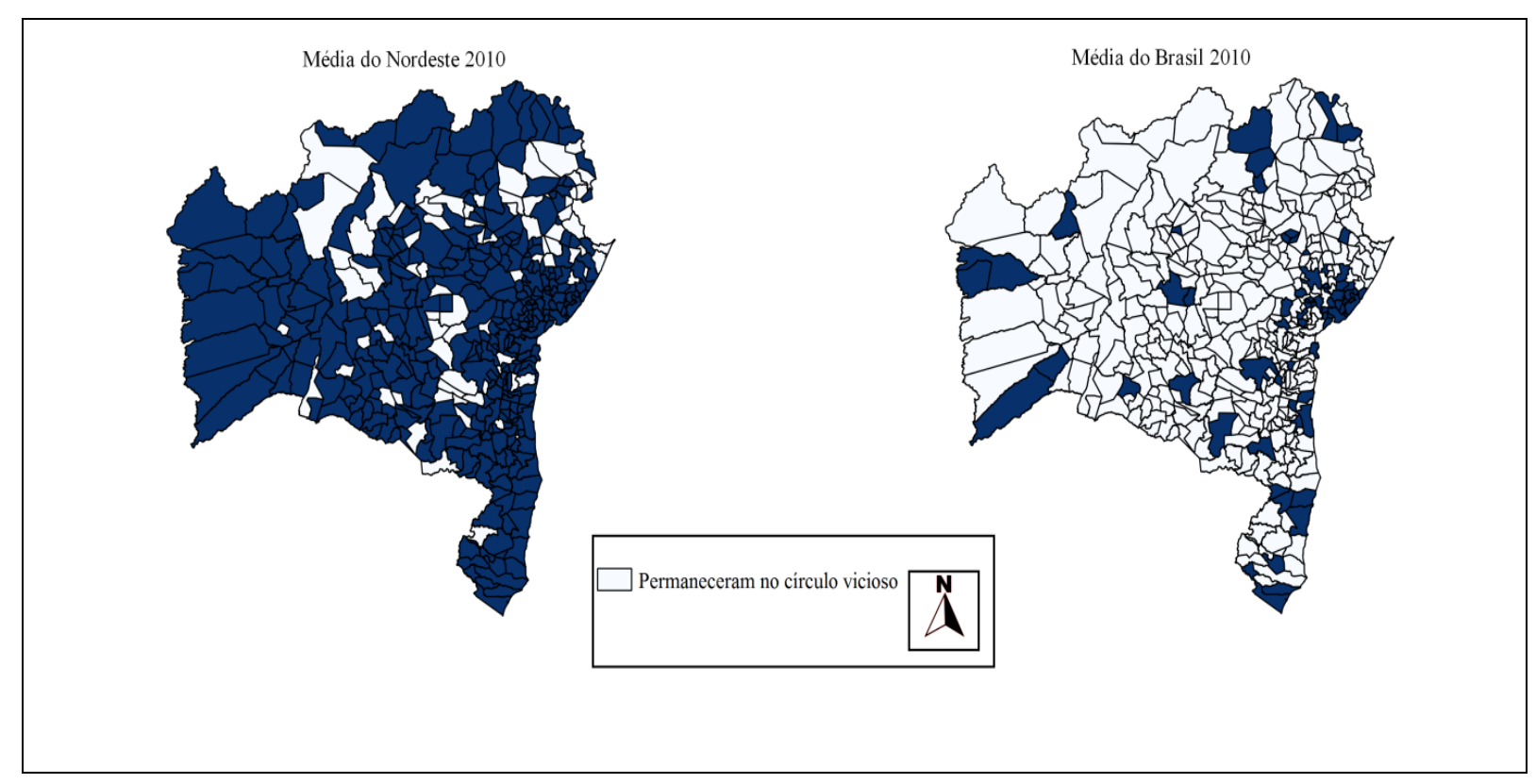

Fonte: Resultados da pesquisa.

Como preconizado em Myrdal (1997), para descontinuar o círculo vicioso do subdesenvolvimento econômico e da pobreza, é imprescindível a realização de intervenções estatais que contribuam para elevar o patamar de desenvolvimento econômico com o propósito de reduzir os índices de pobreza e melhorar o IDHM no estado da Bahia.

\section{Considerações finais}

A desigualdade de renda e a pobreza são características marcantes do Nordeste brasileiro, constituindo-se em um dos seus principais problemas, posto que a região em geral apresenta os piores indicadores de pobreza e desenvolvimento humano do Brasil. Ademais, da mesma maneira, tais desigualdades ocorrem no âmbito intrarregional. Nesse contexto, essa pesquisa buscou proporcionar um melhor entendimento acerca do desenvolvimento socioeconômico do Estado da Bahia, servindo, desta forma, como suporte para possíveis políticas governamentais.

Os principais resultados evidenciaram que a maior parte dos municípios que se encontravam no círculo vicioso da pobreza permaneceram nesta condição e/ou tiveram sua participação ligeiramente reduzida no período analisado. Em contrapartida, aumentou o número dos municípios classificados como tendendo ao desenvolvimento. O padrão de desenvolvimento no Estado da Bahia foi 
caracterizado por ganhos substantivos em termos de indicadores sociais, enquanto os ganhos em termos de crescimento econômico se mostraram inferiores em relação à média nacional.

Diante desse panorama, pode-se dizer que uma vez iniciado o processo de desenvolvimento humano a probabilidade de nele regredir são menores em decorrência do processo cumulativo em que a cada momento são reforçados os elementos necessários para a manutenção do bem-estar de uma sociedade. Pela mesma razão, o processo cumulativo também pode reforçar os efeitos negativos o que justamente apontaram os dados -, já que a grande proporção de municípios classificados no círculo vicioso tiveram depreciados os elementos responsáveis pelo bem-estar de suas populações.

O padrão de desenvolvimento no estado da Bahia, em relação à média brasileira, foi caracterizado por ganhos reforçados em termos de indicadores sociais, enquanto os ganhos em termos de crescimento econômico foram inferiores em relação à média nacional. Passada uma década, pouca foi a redução no número de municípios baianos classificados no círculo vicioso em 2010.

Em vista disso, pode-se inferir que o processo de reversão do subdesenvolvimento no referido espaço vem se mostrando mais lento. Tal lentidão, acredita-se, pode inclusive se ampliar num contexto onde estejam ausentes políticas públicas que visem à ruptura do círculo em questão. Dessa forma, políticas governamentais que promovam o desenvolvimento regional, como efetivo aumento do capital humano existente, a redução na concentração de renda, a elevação no dinamismo econômico, dentre outros, são caminhos que conduzem ao rompimento do subdesenvolvimento humano, isto é, são alternativas de superação do círculo vicioso da pobreza.

\section{REFERÊNCIAS}

BATALHÃO, A. C. S.; PRATES, G. A.; TEIXEIRA, D.; GODOI, E. L. Dimensões do desenvolvimento humano: o caso da região de Ribeirão Preto, SP. Revista Interações, Campo Grande (MS), v. 19, n. 2, p. 237-256, abr./jun. 2018.

COMISIÓN ECONÓMICA PARA AMÉRICA LATINA Y EL CARIBE CEPAL. Pactos para la igualdad: Hacia un futuro sostenible. Santiago. 2014.

CAMPOS, M. M. S. Estado desenvolvimentista e a ampliação das capacitações: uma possível convergência. Cadernos do Desenvolvimento, Rio de Janeiro, v. 9, n. $14,2014$. 
COSTA, D. H; MONDARDO, M. L. A modernização da agricultura no oeste baiano: migração sulista e novas territorialidades. Revista Geonorte, Edição Especial 3, v. 7, n. 1, p. 1347-1361, 2013.

DE OLIVEIRA, G. B. Uma discussão sobre o conceito de desenvolvimento. Revista da FAE, Curitiba (PR), vol. 5, nº 02, p. 37-48, 2002.

GREMAUD, A. P; DE VASCONCELOS, M. A. S.; TONETO JÚNIOR, R. Economia Brasileira Contemporânea. $8^{a}$ ed. São Paulo: Atlas, 2016.

FURTADO, C. Teoria e política do desenvolvimento econômico. São Paulo: Paz e Terra, 2000.

HOBSBAWM, E. Sobre História. São Paulo: Companhia das Letras, 2013.

INFORME SOBRE DESARROLLO HUMANO. La dinámica del desarrollo humano regional. 2002. Disponível em: <http://www.centrodesarrollohumano.org>. Acesso em: 18 jan. 2016.

LIMA, J. F. Géoéconomie et développement regional. Paris: Publibook, 2012.

MILANOVIC, B. Junk the phrase 'Human Capital', 13 feb. 2015. Disponivel em: Acesso em: 13 fev. 2015.

MYRDAL, G. Aspectos políticos da teoria econômica. 2. a ed. São Paulo: Nova Cultural, 1997.

MYRDAL, G. Contra a corrente: ensaios críticos em economia. Rio de Janeiro: Campus, 1977.

MYRDAL, G. Subdesenvolvimento. Brasília: UnB, 1970. 
MYRDAL, G. Teoria econômica e regiões subdesenvolvidas. 2. ${ }^{a}$ ed. Rio de Janeiro: Editora Saga, 1968.

NURKSE, R. Problemas da formação de capital em países subdesenvolvidos. Rio de Janeiro: Editora Civilização Brasileira, 1957.

OLIVEIRA, N. S. M. N.; FERRERA DE LIMA, J.; RAIHER, A. P. Convergência do desenvolvimento humano municipal no Nordeste do Brasil. Revista Brasileira de Gestão e Desenvolvimento Regional, Taubaté (SP), vol. 13, n. 3, p. 164-184, set./dez. 2017.

PNUD - Programa das Nações Unidas para o Desenvolvimento. Atlas do desenvolvimento humano no Brasil 2013. Disponível em: <http://atlasbrasil.org.br/2013/pt/download/>. Acesso em: 05 fev. 2016.

RAIHER, A. P.; FERRERA DE LIMA, J. Desenvolvimento humano municipal no Sul do Brasil: evolução recente e o círculo vicioso da pobreza. Acta Scientiarum. Human and Social Sciences, Maringa (PR), v. 36, n. 02, p. 147154, 2014.

RODRIK, D. The Past, Present, and Future of Economic Growth. Challenge, White Plains, v. 57, n. 3, p. 5-39, 2014.

ROSTOW, W. W. Etapas do Desenvolvimento Econômico: um manifesto não comunista. Rio de Janeiro: Zahar, 1974.

SACHS, I. Desenvolvimento: includente, sustentável, sustentado. Rio de Janeiro: Garamond, 2008.

SANT'ANA, M. The evolution of the concept of development: from economic growth to human development. Louvain-la-Neuve: InterUniversityAttraction Pole, 2008.

SCHULTZ, T. W. Investindo no povo: o segredo econômico da qualidade da população. Rio de Janeiro: Forense Universitária, 1987. 
SEN, A. Como julgar a globalização. In: SEN, A.; KLIKSBERG, B. As pessoas em primeiro lugar: A ética do desenvolvimento e os problemas do mundo globalizado. São Paulo: Companhia das Letras, 2010.

SEN, A. Desigualdade reexaminada. Rio de Janeiro: Record, 2001.

SEN, A. Desenvolvimento como Liberdade. São Paulo: Companhia das Letras, 2000.

SIEDENBERG, D. R. Apontamentos sobre as bases empíricas do desenvolvimento. Revista Brasileira de Desenvolvimento Regional, Blumenau (SC), v. 1, n. 01, p. 33-50, 2013.

SOBRINHO, N. F. S. Desigualdade e Pobreza: fatos estilizados e simulações. Revista Paranaense de Desenvolvimento. Curitiba (PR), n. 100, p. 109-133, 2001.

STIGLITZ, J. The Price of Inequality: how today's divided society endangers our future. New York: W. W. Norton, 2012.

VIANA, G.; FERRERA DE LIMA, J. Capital humano e crescimento econômico. Revista Interações. Campo Grande (MS), v. 11, n. 02, p. 137-148, 2010. 
APÊNDICE - Classificação do Desenvolvimento Humano Municipal da Bahia em relação à média brasileira e à média do Nordeste (2000 e 2010)

\begin{tabular}{|c|c|c|c|c|c|c|}
\hline \multirow{3}{*}{ UF } & \multirow{3}{*}{ Cód. UF } & & Méd & Brasil & Média & Jordeste \\
\hline & & Município & & & & \\
\hline & & & 2000 & 2010 & 2000 & 2010 \\
\hline $\mathrm{BA}$ & 29 & Abaíra & Círculo vicioso & Círculo vicioso & Círculo virtuoso & Tendendo ao crescimento \\
\hline $\mathrm{BA}$ & 29 & Abaré & Círculo vicioso & Círculo vicioso & Tendendo ao crescimento & - \\
\hline $\mathrm{BA}$ & 29 & Acajutiba & Círculo vicioso & Círculo vicioso & - & Círculo vicioso \\
\hline $\mathrm{BA}$ & 29 & Adustina & Círculo vicioso & Círculo vicioso & Tendendo ao crescimento & Círculo vicioso \\
\hline $\mathrm{BA}$ & 29 & Água Fria & Círculo vicioso & Círculo vicioso & $\begin{array}{l}\text { Círculo vicioso } \\
\end{array}$ & Círculo vicioso \\
\hline $\mathrm{BA}$ & 29 & Érico Cardoso & Círculo vicioso & Círculo vicioso & - & - \\
\hline $\mathrm{BA}$ & 29 & Aiquara & Círculo vicioso & $\begin{array}{l}\text { Círculo vicioso } \\
\end{array}$ & Tendendo ao crescimento & Tendendo ao crescimento \\
\hline $\mathrm{BA}$ & 29 & Alagoinhas & Tendendo ao crescimento & Tendendo ao crescimento & Círculo virtuoso & Círculo virtuoso \\
\hline $\mathrm{BA}$ & 29 & Alcobaça & Círculo vicioso & Círculo vicioso & Tendendo ao crescimento & Tendendo ao crescimento \\
\hline $\mathrm{BA}$ & 29 & Almadina & Círculo vicioso & Círculo vicioso & Tendendo ao crescimento & Tendendo ao crescimento \\
\hline $\mathrm{BA}$ & 29 & Amargosa & Círculo vicioso & - & Círculo virtuoso & Círculo virtuoso \\
\hline $\mathrm{BA}$ & 29 & Amélia Rodrigues & - & $\begin{array}{c}\text { Tendendo ao } \\
\text { desenvolvimento }\end{array}$ & Círculo virtuoso & Círculo virtuoso \\
\hline $\mathrm{BA}$ & 29 & América Dourada & Círculo vicioso & Círculo vicioso & Círculo vicioso & Círculo vicioso \\
\hline $\mathrm{BA}$ & 29 & Anagé & Círculo vicioso & Círculo vicioso & Círculo vicioso & - \\
\hline $\mathrm{BA}$ & 29 & Andaraí & Círculo vicioso & Círculo vicioso & Tendendo ao crescimento & - \\
\hline $\mathrm{BA}$ & 29 & Andorinha & Círculo vicioso & Círculo vicioso & Círculo vicioso & Tendendo ao crescimento \\
\hline $\mathrm{BA}$ & 29 & Angical & Círculo vicioso & Círculo vicioso & - & Círculo virtuoso \\
\hline $\mathrm{BA}$ & 29 & Anguera & Círculo vicioso & Círculo vicioso & - & Tendendo ao crescimento \\
\hline $\mathrm{BA}$ & 29 & Antas & Círculo vicioso & Círculo vicioso & Tendendo ao crescimento & Tendendo ao crescimento \\
\hline $\mathrm{BA}$ & 29 & Antônio Cardoso & Círculo vicioso & Círculo vicioso & - & - \\
\hline $\mathrm{BA}$ & 29 & Antônio Gonçalves & Círculo vicioso & Círculo vicioso & - & Tendendo ao crescimento \\
\hline $\mathrm{BA}$ & 29 & Aporá & Círculo vicioso & Círculo vicioso & - & Círculo vicioso \\
\hline $\mathrm{BA}$ & 29 & Apuarema & Círculo vicioso & Círculo vicioso & Círculo vicioso & Círculo vicioso \\
\hline $\mathrm{BA}$ & 29 & Aracatu & Círculo vicioso & Círculo vicioso & - & Tendendo ao crescimento \\
\hline $\mathrm{BA}$ & 29 & Araças & Círculo vicioso & Círculo vicioso & Círculo vicioso & Círculo vicioso \\
\hline $\mathrm{BA}$ & 29 & Araci & Círculo vicioso & Círculo vicioso & Círculo vicioso & Círculo vicioso \\
\hline $\mathrm{BA}$ & 29 & Aramari & Círculo vicioso & Círculo vicioso & Tendendo ao crescimento & Tendendo ao crescimento \\
\hline $\mathrm{BA}$ & 29 & Arataca & Círculo vicioso & Círculo vicioso & Círculo vicioso & - \\
\hline $\mathrm{BA}$ & 29 & Aratuípe & Círculo vicioso & Círculo vicioso & Tendendo ao crescimento & Tendendo ao crescimento \\
\hline $\mathrm{BA}$ & 29 & Aurelino Leal & Círculo vicioso & Círculo vicioso & Círculo vicioso & - \\
\hline $\mathrm{BA}$ & 29 & Baianópolis & Círculo vicioso & Círculo vicioso & Círculo vicioso & Tendendo ao desenvolvimento \\
\hline $\mathrm{BA}$ & 29 & Baixa Grande & Círculo vicioso & Círculo vicioso & - & - \\
\hline $\mathrm{BA}$ & 29 & Banzaê & Círculo vicioso & Círculo vicioso & Círculo vicioso & - \\
\hline $\mathrm{BA}$ & 29 & Barra & Círculo vicioso & Círculo vicioso & Círculo vicioso & Círculo vicioso \\
\hline $\mathrm{BA}$ & 29 & Barra da Estiva & Círculo vicioso & Círculo vicioso & Tendendo ao crescimento & Tendendo ao crescimento \\
\hline $\mathrm{BA}$ & 29 & Barra do Choça & Círculo vicioso & Círculo vicioso & Círculo vicioso & Tendendo ao crescimento \\
\hline $\mathrm{BA}$ & 29 & Barra do Mendes & Círculo vicioso & Círculo vicioso & Círculo virtuoso & Tendendo ao desenvolvimento \\
\hline $\mathrm{BA}$ & 29 & Barra do Rocha & Círculo vicioso & Círculo vicioso & Tendendo ao crescimento & Tendendo ao crescimento \\
\hline $\mathrm{BA}$ & 29 & Barreiras & Tendendo ao crescimento & Círculo virtuoso & Círculo virtuoso & Círculo virtuoso \\
\hline $\mathrm{BA}$ & 29 & Barro Alto & Círculo vicioso & $\begin{array}{l}\text { Círculo vicioso } \\
\end{array}$ & - & - \\
\hline $\mathrm{BA}$ & 29 & Barrocas & Círculo vicioso & Círculo vicioso & Tendendo ao crescimento & Círculo virtuoso \\
\hline $\mathrm{BA}$ & 29 & Barro Preto & Círculo vicioso & Círculo vicioso & Tendendo ao crescimento & Tendendo ao crescimento \\
\hline $\mathrm{BA}$ & 29 & Belmonte & Círculo vicioso & Círculo vicioso & Tendendo ao crescimento & Tendendo ao crescimento \\
\hline $\mathrm{BA}$ & 29 & Belo Campo & Círculo vicioso & Círculo vicioso & Tendendo ao crescimento & - \\
\hline $\mathrm{BA}$ & 29 & Biritinga & Círculo vicioso & Círculo vicioso & Círculo vicioso & Círculo vicioso \\
\hline $\mathrm{BA}$ & 29 & Boa Nova & Círculo vicioso & Círculo vicioso & Círculo vicioso & Círculo vicioso \\
\hline $\mathrm{BA}$ & 29 & Boa Vista do Tupim & Círculo vicioso & Círculo vicioso & Círculo vicioso & Círculo vicioso \\
\hline $\mathrm{BA}$ & 29 & Bom Jesus da Lapa & Círculo vicioso & Círculo vicioso & Tendendo ao crescimento & Círculo virtuoso \\
\hline $\mathrm{BA}$ & 29 & Bom Jesus da Serra & Círculo vicioso & Círculo vicioso & Círculo vicioso & Círculo vicioso \\
\hline $\mathrm{BA}$ & 29 & Boninal & Círculo vicioso & Círculo vicioso & - & Círculo virtuoso \\
\hline $\mathrm{BA}$ & 29 & Bonito & Círculo vicioso & Círculo vicioso & Círculo vicioso & Círculo vicioso \\
\hline $\mathrm{BA}$ & 29 & Boquira & Círculo vicioso & Círculo vicioso & Tendendo ao crescimento & Círculo virtuoso \\
\hline $\mathrm{BA}$ & 29 & Botuporã & Círculo vicioso & Círculo vicioso & - & Círculo vicioso \\
\hline $\mathrm{BA}$ & 29 & Brejões & Círculo vicioso & Círculo vicioso & Tendendo ao crescimento & Tendendo ao desenvolvimento \\
\hline $\mathrm{BA}$ & 29 & Brejolândia & Círculo vicioso & Círculo vicioso & - & - \\
\hline $\mathrm{BA}$ & 29 & Brotas de Macaúbas & Círculo vicioso & Círculo vicioso & Círculo vicioso & Círculo vicioso \\
\hline $\mathrm{BA}$ & 29 & Brumado & Círculo vicioso & - & Círculo virtuoso & Círculo virtuoso \\
\hline $\mathrm{BA}$ & 29 & Buerarema & Círculo vicioso & Círculo vicioso & Tendendo ao crescimento & Círculo virtuoso \\
\hline $\mathrm{BA}$ & 29 & Buritirama & Círculo vicioso & Círculo vicioso & Círculo vicioso & - \\
\hline $\mathrm{BA}$ & 29 & Caatiba & Círculo vicioso & Círculo vicioso & Círculo vicioso & Tendendo ao crescimento \\
\hline $\mathrm{BA}$ & 29 & Cabaceiras do Paraguaçu & Círculo vicioso & Círculo vicioso & Círculo vicioso & Tendendo ao desenvolvimento \\
\hline $\mathrm{BA}$ & 29 & Cachoeira & - & - & Círculo virtuoso & Círculo virtuoso \\
\hline $\mathrm{BA}$ & 29 & Caculé & Tendendo ao crescimento & Círculo vicioso & Círculo virtuoso & Círculo virtuoso \\
\hline $\mathrm{BA}$ & 29 & Caém & Círculo vicioso & Círculo vicioso & Círculo vicioso & Círculo vicioso \\
\hline $\mathrm{BA}$ & 29 & Caetanos & Círculo vicioso & Círculo vicioso & Círculo vicioso & Círculo vicioso \\
\hline $\mathrm{BA}$ & 29 & Caetité & - & Círculo vicioso & Círculo virtuoso & Tendendo ao crescimento \\
\hline $\mathrm{BA}$ & 29 & Cafarnaum & Círculo vicioso & Círculo vicioso & Tendendo ao crescimento & - \\
\hline $\mathrm{BA}$ & 29 & Cairu & Círculo vicioso & - & Círculo virtuoso & Círculo virtuoso \\
\hline $\mathrm{BA}$ & 29 & Caldeirão Grande & Círculo vicioso & Círculo vicioso & Círculo vicioso & - \\
\hline $\mathrm{BA}$ & 29 & Camacan & Círculo vicioso & Círculo vicioso & Tendendo ao crescimento & Tendendo ao crescimento \\
\hline $\mathrm{BA}$ & 29 & Camaçari & Tendendo ao crescimento & Tendendo ao crescimento & Círculo virtuoso & Círculo virtuoso \\
\hline $\mathrm{BA}$ & 29 & Camamu & Círculo vicioso & Círculo vicioso & - & Círculo vicioso \\
\hline $\mathrm{BA}$ & 29 & Campo Alegre de Lourdes & Círculo vicioso & Círculo vicioso & Tendendo ao crescimento & - \\
\hline $\mathrm{BA}$ & 29 & Campo Formoso & Círculo vicioso & Círculo vicioso & Tendendo ao crescimento & Tendendo ao crescimento \\
\hline $\mathrm{BA}$ & 29 & Canápolis & Círculo vicioso & Círculo vicioso & Círculo virtuoso & Círculo vicioso \\
\hline $\mathrm{BA}$ & 29 & Canarana & Círculo vicioso & Círculo vicioso & Tendendo ao crescimento & - \\
\hline $\mathrm{BA}$ & 29 & Canavieiras & Círculo vicioso & Círculo vicioso & Tendendo ao crescimento & Tendendo ao crescimento \\
\hline $\mathrm{BA}$ & 29 & Candeal & Círculo vicioso & Círculo vicioso & Tendendo ao desenvolvimento & - \\
\hline $\mathrm{BA}$ & 29 & Candeias & Tendendo ao crescimento & $\begin{array}{l}\text { Círculo virtuoso } \\
\end{array}$ & $\begin{array}{c}\text { Círculo virtuoso } \\
\end{array}$ & Círculo virtuoso \\
\hline $\mathrm{BA}$ & 29 & Candiba & Círculo vicioso & Círculo vicioso & Tendendo ao desenvolvimento & Tendendo ao crescimento \\
\hline $\mathrm{BA}$ & 29 & Cândido Sales & Círculo vicioso & Círculo vicioso & Tendendo ao crescimento & Tendendo ao crescimento \\
\hline $\mathrm{BA}$ & 29 & CansançÃo & Círculo vicioso & Círculo vicioso & Círculo vicioso & Círculo vicioso \\
\hline $\mathrm{BA}$ & 29 & Canudos & Círculo vicioso & Círculo vicioso & Círculo vicioso & Círculo vicioso \\
\hline $\mathrm{BA}$ & 29 & Capela do Alto Alegre & Círculo vicioso & Círculo vicioso & Círculo virtuoso & Tendendo ao crescimento \\
\hline $\mathrm{BA}$ & 29 & Capim Grosso & Círculo vicioso & Círculo vicioso & Tendendo ao crescimento & Tendendo ao crescimento \\
\hline
\end{tabular}




\begin{tabular}{|c|c|c|c|c|c|}
\hline $\mathrm{BA}$ & 29 & Caraíbas & Círculo vicioso & Círculo vicioso & Círculo vicioso \\
\hline $\mathrm{BA}$ & 29 & $\begin{array}{l}\text { Caravelas } \\
\end{array}$ & Tendendo ao crescimento & Círculo vicioso & $\begin{array}{l}\text { Círculo virtuoso } \\
\end{array}$ \\
\hline $\mathrm{BA}$ & 29 & $\begin{array}{l}\text { Cardeal da Silva } \\
\end{array}$ & Círculo vicioso & Círculo vicioso & $\begin{array}{l}\text { Círculo vicioso } \\
\end{array}$ \\
\hline $\mathrm{BA}$ & 29 & Carinhanha & Círculo vicioso & Círculo vicioso & $\begin{array}{l}\text { Círculo vicioso } \\
\end{array}$ \\
\hline $\mathrm{BA}$ & 29 & Casa Nova & Círculo vicioso & $\begin{array}{l}\text { Círculo vicioso } \\
\end{array}$ & Tendendo ao crescimento \\
\hline $\mathrm{BA}$ & 29 & Castro Alves & Círculo vicioso & Círculo vicioso & Círculo virtuoso \\
\hline $\mathrm{BA}$ & 29 & Catolândia & $\begin{array}{l}\text { Círculo vicioso } \\
\end{array}$ & Círculo vicioso & Tendendo ao desenvolvimento \\
\hline $\mathrm{BA}$ & 29 & Catu & Tendendo ao crescimento & Círculo virtuoso & $\begin{array}{l}\text { Círculo virtuoso } \\
\end{array}$ \\
\hline $\mathrm{BA}$ & 29 & Caturama & Círculo vicioso & $\begin{array}{l}\text { Círculo vicioso } \\
\end{array}$ & Círculo vicioso \\
\hline $\mathrm{BA}$ & 29 & Central & Círculo vicioso & Círculo vicioso & Tendendo ao crescimento \\
\hline $\mathrm{BA}$ & 29 & Chorrochó & Círculo vicioso & Círculo vicioso & - \\
\hline $\mathrm{BA}$ & 29 & Cícero Dantas & Círculo vicioso & Círculo vicioso & Tendendo ao crescimento \\
\hline $\mathrm{BA}$ & 29 & Cipó & Círculo vicioso & Círculo vicioso & Tendendo ao crescimento \\
\hline $\mathrm{BA}$ & 29 & Coaraci & Círculo vicioso & Círculo vicioso & Tendendo ao crescimento \\
\hline $\mathrm{BA}$ & 29 & Cocos & Círculo vicioso & - & Tendendo ao crescimento \\
\hline $\mathrm{BA}$ & 29 & Conceição da Feira & - & Círculo vicioso & Tendendo ao crescimento \\
\hline $\mathrm{BA}$ & 29 & Conceição do Almeida & Círculo vicioso & - & Círculo virtuoso \\
\hline $\mathrm{BA}$ & 29 & Conceição do Coité & Círculo vicioso & Círculo vicioso & Tendendo ao crescimento \\
\hline $\mathrm{BA}$ & 29 & Conceição do Jacuípe & - & - & Círculo virtuoso \\
\hline $\mathrm{BA}$ & 29 & Conde & Círculo vicioso & Círculo vicioso & Círculo vicioso \\
\hline $\mathrm{BA}$ & 29 & Conde $\cdot \mathrm{ba}$ & Círculo vicioso & Círculo vicioso & Tendendo ao crescimento \\
\hline $\mathrm{BA}$ & 29 & Contendas do Sincorá & Círculo vicioso & Círculo vicioso & Tendendo ao crescimento \\
\hline $\mathrm{BA}$ & 29 & Coração de Maria & Círculo vicioso & Círculo vicioso & Tendendo ao crescimento \\
\hline $\mathrm{BA}$ & 29 & $\begin{array}{l}\text { Cordeiros } \\
\end{array}$ & Círculo vicioso & Círculo vicioso & - \\
\hline $\mathrm{BA}$ & 29 & $\begin{array}{l}\text { Coribe } \\
\end{array}$ & Círculo vicioso & - & - \\
\hline $\mathrm{BA}$ & 29 & Coronel João Sá & Círculo vicioso & Círculo vicioso & Círculo vicioso \\
\hline $\mathrm{BA}$ & 29 & Correntina & Círculo vicioso & Círculo vicioso & Círculo virtuoso \\
\hline $\mathrm{BA}$ & 29 & Cotegipe & Círculo vicioso & Círculo vicioso & Círculo vicioso \\
\hline $\mathrm{BA}$ & 29 & Cravolândia & Círculo vicioso & Círculo vicioso & Tendendo ao desenvolvimento \\
\hline $\mathrm{BA}$ & 29 & $\begin{array}{l}\text { Crisópolis } \\
\end{array}$ & Círculo vicioso & Círculo vicioso & Círculo vicioso \\
\hline $\mathrm{BA}$ & 29 & Cristópolis & Círculo vicioso & Círculo vicioso & Tendendo ao desenvolvimento \\
\hline $\mathrm{BA}$ & 29 & Cruz das Almas & Tendendo ao crescimento & Tendendo ao crescimento & Círculo virtuoso \\
\hline $\mathrm{BA}$ & 29 & Curaçá & Círculo vicioso & Círculo vicioso & Tendendo ao crescimento \\
\hline $\mathrm{BA}$ & 29 & Dário Meira & Círculo vicioso & Círculo vicioso & Círculo vicioso \\
\hline $\mathrm{BA}$ & 29 & Dias D'Ávila & Tendendo ao crescimento & Círculo virtuoso & Círculo virtuoso \\
\hline $\mathrm{BA}$ & 29 & Dom Basílio & Círculo vicioso & $\begin{array}{l}\text { Círculo vicioso } \\
\end{array}$ & $\begin{array}{l}\text { Círculo virtuoso } \\
\end{array}$ \\
\hline $\mathrm{BA}$ & 29 & Dom Macedo Costa & Círculo vicioso & Círculo vicioso & $\begin{array}{l}\text { Círculo virtuoso } \\
\end{array}$ \\
\hline $\mathrm{BA}$ & 29 & ElÍsio Medrado & Círculo vicioso & Círculo vicioso & Círculo virtuoso \\
\hline $\mathrm{BA}$ & 29 & Encruzilhada & Círculo vicioso & Círculo vicioso & - \\
\hline $\mathrm{BA}$ & 29 & Entre Rios & Círculo vicioso & Círculo vicioso & $\begin{array}{l}\text { Círculo virtuoso } \\
\end{array}$ \\
\hline $\mathrm{BA}$ & 29 & $\begin{array}{l}\text { Esplanada } \\
\end{array}$ & Círculo vicioso & Círculo vicioso & Tendendo ao crescimento \\
\hline $\mathrm{BA}$ & 29 & Euclides da Cunha & $\begin{array}{l}\text { Círculo vicioso } \\
\end{array}$ & $\begin{array}{l}\text { Círculo vicioso } \\
\end{array}$ & Tendendo ao crescimento \\
\hline $\mathrm{BA}$ & 29 & Eunápolis & Tendendo ao crescimento & Tendendo ao crescimento & Círculo virtuoso \\
\hline $\mathrm{BA}$ & 29 & $\begin{array}{l}\text { Fátima } \\
\end{array}$ & Círculo vicioso & Círculo vicioso & Tendendo ao crescimento \\
\hline $\mathrm{BA}$ & 29 & Feira da Mata & Círculo vicioso & $\begin{array}{l}\text { Círculo vicioso } \\
\end{array}$ & Tendendo ao crescimento \\
\hline $\mathrm{BA}$ & 29 & Feira de Santana & Tendendo ao crescimento & $\begin{array}{l}\text { Círculo virtuoso } \\
\end{array}$ & Círculo virtuoso \\
\hline $\mathrm{BA}$ & 29 & $\begin{array}{l}\text { Filadélfia } \\
\end{array}$ & Círculo vicioso & $\begin{array}{l}\text { Círculo vicioso } \\
\end{array}$ & $\begin{array}{l}\text { Círculo vicioso } \\
\end{array}$ \\
\hline $\mathrm{BA}$ & 29 & Firmino Alves & Círculo vicioso & Círculo vicioso & Círculo virtuoso \\
\hline $\mathrm{BA}$ & 29 & Floresta Azul & Círculo vicioso & Círculo vicioso & Círculo virtuoso \\
\hline $\mathrm{BA}$ & 29 & Formosa do Rio Preto & Círculo vicioso & Círculo vicioso & Tendendo ao crescimento \\
\hline $\mathrm{BA}$ & 29 & Gandu & Tendendo ao crescimento & Tendendo ao crescimento & Círculo virtuoso \\
\hline $\mathrm{BA}$ & 29 & Gavião & Círculo vicioso & Círculo vicioso & Tendendo ao crescimento \\
\hline $\mathrm{BA}$ & 29 & Gentio do Ouro & Círculo vicioso & Círculo vicioso & Tendendo ao crescimento \\
\hline $\mathrm{BA}$ & 29 & Glória & Círculo vicioso & Círculo vicioso & Tendendo ao crescimento \\
\hline $\mathrm{BA}$ & 29 & Gongogi & Círculo vicioso & Círculo vicioso & Círculo vicioso \\
\hline BA & 29 & $\begin{array}{l}\text { Governador } \\
\text { Mangabeira } \\
\end{array}$ & 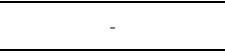 & 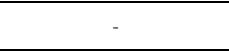 & Círculo virtuoso \\
\hline $\mathrm{BA}$ & 29 & Guajeru & Círculo vicioso & Círculo vicioso & Tendendo ao crescimento \\
\hline $\mathrm{BA}$ & 29 & Guanambi & Tendendo ao crescimento & Tendendo ao crescimento & Círculo virtuoso \\
\hline $\mathrm{BA}$ & 29 & Guaratinga & Círculo vicioso & Círculo vicioso & Tendendo ao crescimento \\
\hline $\mathrm{BA}$ & 29 & Heliópolis & Círculo vicioso & Círculo vicioso & Círculo vicioso \\
\hline $\mathrm{BA}$ & 29 & Iaçu & Círculo vicioso & Círculo vicioso & Tendendo ao crescimento \\
\hline $\mathrm{BA}$ & 29 & Ibiassucê & Círculo vicioso & Círculo vicioso & Tendendo ao crescimento \\
\hline $\mathrm{BA}$ & 29 & Ibicaraí & Círculo vicioso & Círculo vicioso & Tendendo ao crescimento \\
\hline $\mathrm{BA}$ & 29 & Ibicoara & Círculo vicioso & Círculo vicioso & Tendendo ao crescimento \\
\hline $\mathrm{BA}$ & 29 & Ibicuí & Círculo vicioso & Círculo vicioso & Tendendo ao crescimento \\
\hline $\mathrm{BA}$ & 29 & Ibipeba & Círculo vicioso & Círculo vicioso & Tendendo ao crescimento \\
\hline $\mathrm{BA}$ & 29 & Ibipitanga & Círculo vicioso & Círculo vicioso & Tendendo ao crescimento \\
\hline $\mathrm{BA}$ & 29 & Ibiquera & Círculo vicioso & Círculo vicioso & Círculo vicioso \\
\hline $\mathrm{BA}$ & 29 & Ibirapitanga & Círculo vicioso & Círculo vicioso & Círculo vicioso \\
\hline $\mathrm{BA}$ & 29 & Ibirapuã & Círculo vicioso & Círculo vicioso & Círculo virtuoso \\
\hline$\overline{\mathrm{BA}}$ & 29 & Ibirataia & Círculo vicioso & Círculo vicioso & Tendendo ao crescimento \\
\hline $\mathrm{BA}$ & 29 & Ibitiara & Círculo vicioso & Círculo vicioso & Tendendo ao crescimento \\
\hline $\mathrm{BA}$ & 29 & Ibititá & Círculo vicioso & Círculo vicioso & Tendendo ao crescimento \\
\hline $\mathrm{BA}$ & 29 & Ibotirama & Círculo vicioso & Círculo vicioso & Círculo virtuoso \\
\hline $\mathrm{BA}$ & 29 & $\begin{array}{ll}\text { Ichu } \\
\end{array}$ & - & - & $\begin{array}{l}\text { Círculo virtuoso } \\
\end{array}$ \\
\hline $\mathrm{BA}$ & 29 & Igaporã & Círculo vicioso & Círculo vicioso & $\begin{array}{l}\text { Círculo virtuoso } \\
\end{array}$ \\
\hline $\mathrm{BA}$ & 29 & Igrapiúna & Círculo vicioso & Círculo vicioso & - \\
\hline $\mathrm{BA}$ & 29 & Iguaí & Círculo vicioso & $\begin{array}{l}\text { Círculo vicioso } \\
\end{array}$ & Tendendo ao crescimento \\
\hline $\mathrm{BA}$ & 29 & Ilhéus & Tendendo ao crescimento & Círculo virtuoso & Círculo virtuoso \\
\hline $\mathrm{BA}$ & 29 & Inhambupe & Círculo vicioso & $\begin{array}{l}\text { Círculo vicioso } \\
\end{array}$ & $\begin{array}{l}\text { Círculo vicioso } \\
\end{array}$ \\
\hline $\mathrm{BA}$ & 29 & Ipecaetá & $\begin{array}{l}\text { Círculo vicioso } \\
\end{array}$ & $\begin{array}{l}\text { Círculo vicioso } \\
\end{array}$ & $\begin{array}{l}\text { Círculo vicioso } \\
\end{array}$ \\
\hline $\mathrm{BA}$ & 29 & Ipiaú & Tendendo ao crescimento & Tendendo ao crescimento & Círculo virtuoso \\
\hline $\mathrm{BA}$ & 29 & Ipirá & Círculo vicioso & Círculo vicioso & Tendendo ao crescimento \\
\hline $\mathrm{BA}$ & 29 & Ipupiara & Círculo vicioso & Círculo vicioso & Círculo virtuoso \\
\hline $\mathrm{BA}$ & 29 & Irajuba & Círculo vicioso & Círculo vicioso & $\begin{array}{l}\text { Círculo vicioso } \\
\end{array}$ \\
\hline $\mathrm{BA}$ & 29 & Iramaia & Círculo vicioso & Círculo vicioso & - \\
\hline $\mathrm{BA}$ & 29 & Iraquara & Círculo vicioso & Círculo vicioso & - \\
\hline $\mathrm{BA}$ & 29 & Irará & Círculo vicioso & - & Círculo virtuoso \\
\hline $\mathrm{BA}$ & 29 & Irecề & Tendendo ao crescimento & Tendendo ao crescimento & Tendendo ao crescimento \\
\hline $\mathrm{BA}$ & 29 & Itabela & Círculo vicioso & Círculo vicioso & Tendendo ao crescimento \\
\hline $\mathrm{BA}$ & 29 & Itaberaba & $\begin{array}{l}\text { Círculo vicioso } \\
\end{array}$ & Círculo vicioso & Tendendo ao crescimento \\
\hline $\mathrm{BA}$ & 29 & Itabuna & Círculo virtuoso & Círculo virtuoso & Círculo virtuoso \\
\hline $\mathrm{BA}$ & 29 & Itacaré & 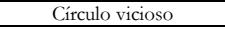 & - & Tendendo ao crescimento \\
\hline
\end{tabular}




\begin{tabular}{|c|c|c|c|c|}
\hline $\mathrm{BA}$ & 29 & Itaeté & Círculo vicioso & Círculo vicioso \\
\hline $\mathrm{BA}$ & 29 & Itagi & Círculo vicioso & Círculo vicioso \\
\hline $\mathrm{BA}$ & 29 & Itagibá & Círculo vicioso & Círculo vicioso \\
\hline $\mathrm{BA}$ & 29 & Itagimirim & Círculo vicioso & - \\
\hline $\mathrm{BA}$ & 29 & Itaguaçu da Bahia & Círculo vicioso & Círculo vicioso \\
\hline $\mathrm{BA}$ & 29 & Itaju do Colônia & Círculo vicioso & Círculo vicioso \\
\hline $\mathrm{BA}$ & 29 & Itajuípe & Círculo vicioso & Círculo vicioso \\
\hline $\mathrm{BA}$ & 29 & Itamaraju & Tendendo ao crescimento & Círculo vicioso \\
\hline $\mathrm{BA}$ & 29 & Itamari & Círculo vicioso & Círculo vicioso \\
\hline $\mathrm{BA}$ & 29 & Itambé & Círculo vicioso & Círculo vicioso \\
\hline $\mathrm{BA}$ & 29 & Itanagra & Círculo vicioso & Círculo vicioso \\
\hline $\mathrm{BA}$ & 29 & Itanhém & Círculo vicioso & Círculo vicioso \\
\hline $\mathrm{BA}$ & 29 & Itaparica & - & Tendendo ao crescimento \\
\hline $\mathrm{BA}$ & 29 & Itapé & Círculo vicioso & Círculo vicioso \\
\hline $\mathrm{BA}$ & 29 & Itapebi & Círculo vicioso & Círculo vicioso \\
\hline $\mathrm{BA}$ & 29 & Itapetinga & Tendendo ao crescimento & Tendendo ao crescimento \\
\hline $\mathrm{BA}$ & 29 & Itapicuru & Círculo vicioso & Círculo vicioso \\
\hline $\mathrm{BA}$ & 29 & Itapitanga & Círculo vicioso & Círculo vicioso \\
\hline $\mathrm{BA}$ & 29 & Itaquara & Círculo vicioso & Círculo vicioso \\
\hline $\mathrm{BA}$ & 29 & Itarantim & Círculo vicioso & Círculo vicioso \\
\hline $\mathrm{BA}$ & 29 & Itatim & Círculo vicioso & Círculo vicioso \\
\hline $\mathrm{BA}$ & 29 & Itiruçu & Círculo vicioso & Círculo vicioso \\
\hline $\mathrm{BA}$ & 29 & Itiúba & Círculo vicioso & Círculo vicioso \\
\hline $\mathrm{BA}$ & 29 & Itororó & Círculo vicioso & Círculo vicioso \\
\hline $\mathrm{BA}$ & 29 & Ituaçu & Círculo vicioso & Círculo vicioso \\
\hline $\mathrm{BA}$ & 29 & Ituberá & Círculo vicioso & Círculo vicioso \\
\hline $\mathrm{BA}$ & 29 & Iuiú & Círculo vicioso & Círculo vicioso \\
\hline $\mathrm{BA}$ & 29 & Jaborandi & Círculo vicioso & Círculo vicioso \\
\hline $\mathrm{BA}$ & 29 & Jacaraci & $\begin{array}{l}\text { Círculo vicioso } \\
\end{array}$ & Círculo vicioso \\
\hline $\mathrm{BA}$ & 29 & Jacobina & Tendendo ao crescimento & Círculo vicioso \\
\hline $\mathrm{BA}$ & 29 & Jaguaquara & Círculo vicioso & Círculo vicioso \\
\hline $\mathrm{BA}$ & 29 & Jaguarari & Círculo vicioso & Tendendo ao crescimento \\
\hline $\mathrm{BA}$ & 29 & Jaguaripe & Círculo vicioso & Círculo vicioso \\
\hline $\mathrm{BA}$ & 29 & JandaIra & Círculo vicioso & Círculo vicioso \\
\hline $\mathrm{BA}$ & 29 & Jequié & Círculo vicioso & Tendendo ao crescimento \\
\hline $\mathrm{BA}$ & 29 & Jeremoabo & Círculo vicioso & Círculo vicioso \\
\hline $\mathrm{BA}$ & 29 & Jiquiriçá & Círculo vicioso & Círculo vicioso \\
\hline $\mathrm{BA}$ & 29 & Jitaúna & Círculo vicioso & Círculo vicioso \\
\hline $\mathrm{BA}$ & 29 & João Dourado & Círculo vicioso & Círculo vicioso \\
\hline $\mathrm{BA}$ & 29 & Juazeiro & Tendendo ao crescimento & Tendendo ao crescimento \\
\hline $\mathrm{BA}$ & 29 & Jucuruçu & Círculo vicioso & Círculo vicioso \\
\hline $\mathrm{BA}$ & 29 & Jussara & Círculo vicioso & Círculo vicioso \\
\hline$\overline{\mathrm{BA}}$ & 29 & Jussari & Círculo vicioso & Círculo vicioso \\
\hline $\mathrm{BA}$ & 29 & Jussiape & Círculo vicioso & Círculo vicioso \\
\hline $\mathrm{BA}$ & 29 & Lafaiete Coutinho & Círculo vicioso & Círculo vicioso \\
\hline $\mathrm{BA}$ & 29 & Lagoa Real & Círculo vicioso & Círculo vicioso \\
\hline $\mathrm{BA}$ & 29 & Laje & Círculo vicioso & Círculo vicioso \\
\hline $\mathrm{BA}$ & 29 & Lajedão & Tendendo ao crescimento & Tendendo ao crescimento \\
\hline $\mathrm{BA}$ & 29 & Lajedinho & Círculo vicioso & Círculo vicioso \\
\hline $\mathrm{BA}$ & 29 & Lajedo do Tabocal & Círculo vicioso & Círculo vicioso \\
\hline $\mathrm{BA}$ & 29 & Lamarão & Círculo vicioso & Círculo vicioso \\
\hline $\mathrm{BA}$ & 29 & Lapão & Círculo vicioso & Círculo vicioso \\
\hline $\mathrm{BA}$ & 29 & Lauro de Freitas & $\begin{array}{l}\text { Círculo virtuoso } \\
\end{array}$ & $\begin{array}{l}\text { Círculo virtuoso } \\
\end{array}$ \\
\hline $\mathrm{BA}$ & 29 & Lençóis & Círculo vicioso & Círculo vicioso \\
\hline $\mathrm{BA}$ & 29 & $\begin{array}{l}\text { Licínio de Almeida } \\
\end{array}$ & Círculo vicioso & Círculo vicioso \\
\hline $\mathrm{BA}$ & 29 & Livramento de Nossa Senhora & Círculo vicioso & Círculo vicioso \\
\hline $\mathrm{BA}$ & 29 & $\begin{array}{l}\text { Luis Eduardo Magalhães } \\
\end{array}$ & Tendendo ao crescimento & Círculo virtuoso \\
\hline $\mathrm{BA}$ & 29 & Macajuba & Círculo vicioso & Círculo vicioso \\
\hline $\mathrm{BA}$ & 29 & Macarani & Círculo vicioso & Círculo vicioso \\
\hline $\mathrm{BA}$ & 29 & Macaúbas & Círculo vicioso & Círculo vicioso \\
\hline $\mathrm{BA}$ & 29 & Macururé & Círculo vicioso & Círculo vicioso \\
\hline $\mathrm{BA}$ & 29 & Madre de Deus & Tendendo ao crescimento & Tendendo ao crescimento \\
\hline $\mathrm{BA}$ & 29 & Maetinga & $\begin{array}{l}\text { Círculo vicioso } \\
\end{array}$ & $\begin{array}{l}\text { Círculo vicioso } \\
\end{array}$ \\
\hline $\mathrm{BA}$ & 29 & Maiquinique & Círculo vicioso & Círculo vicioso \\
\hline $\mathrm{BA}$ & 29 & Mairi & Círculo vicioso & Círculo vicioso \\
\hline $\mathrm{BA}$ & 29 & Malhada & Círculo vicioso & Círculo vicioso \\
\hline $\mathrm{BA}$ & 29 & Malhada de Pedras & Círculo vicioso & Círculo vicioso \\
\hline $\mathrm{BA}$ & 29 & Manoel Vitorino & Círculo vicioso & Círculo vicioso \\
\hline $\mathrm{BA}$ & 29 & Mansidão & Círculo vicioso & - \\
\hline $\mathrm{BA}$ & 29 & $\begin{array}{l}\text { Maracás } \\
\end{array}$ & Círculo vicioso & Círculo vicioso \\
\hline $\mathrm{BA}$ & 29 & Maragogipe & Círculo vicioso & Círculo vicioso \\
\hline $\mathrm{BA}$ & 29 & Maraú & Círculo vicioso & Círculo vicioso \\
\hline $\mathrm{BA}$ & 29 & Marcionílio Souza & Círculo vicioso & Círculo vicioso \\
\hline $\mathrm{BA}$ & 29 & Mascote & Círculo vicioso & Círculo vicioso \\
\hline $\mathrm{BA}$ & 29 & Mata de São João & Círculo vicioso & Círculo virtuoso \\
\hline $\mathrm{BA}$ & 29 & Matina & Círculo vicioso & Círculo vicioso \\
\hline $\mathrm{BA}$ & 29 & Medeiros Neto & Tendendo ao crescimento & Círculo vicioso \\
\hline $\mathrm{BA}$ & 29 & Miguel Calmon & Círculo vicioso & Círculo vicioso \\
\hline $\mathrm{BA}$ & 29 & Milagres & Círculo vicioso & Círculo vicioso \\
\hline $\mathrm{BA}$ & 29 & Mirangaba & Círculo vicioso & Círculo vicioso \\
\hline $\mathrm{BA}$ & 29 & Mirante & Círculo vicioso & Círculo vicioso \\
\hline $\mathrm{BA}$ & 29 & Monte Santo & Círculo vicioso & Círculo vicioso \\
\hline $\mathrm{BA}$ & 29 & Morpará & Círculo vicioso & Círculo vicioso \\
\hline $\mathrm{BA}$ & 29 & Morro do Chapéu & Círculo vicioso & Círculo vicioso \\
\hline $\mathrm{BA}$ & 29 & Mortugaba & - & Círculo vicioso \\
\hline $\mathrm{BA}$ & 29 & Mucugê & Círculo vicioso & Círculo vicioso \\
\hline $\mathrm{BA}$ & 29 & Mucuri & Tendendo ao crescimento & Tendendo ao crescimento \\
\hline $\mathrm{BA}$ & 29 & Mulungu do Morro & Círculo vicioso & Círculo vicioso \\
\hline $\mathrm{BA}$ & 29 & Mundo Novo & Círculo vicioso & Círculo vicioso \\
\hline $\mathrm{BA}$ & 29 & Muniz Ferreira & Círculo vicioso & Círculo vicioso \\
\hline $\mathrm{BA}$ & 29 & Muquém de São Francisco & Círculo vicioso & Círculo vicioso \\
\hline $\mathrm{BA}$ & 29 & Muritiba & - & - \\
\hline $\mathrm{BA}$ & 29 & Mutuípe & Tendendo ao crescimento & Círculo vicioso \\
\hline $\mathrm{BA}$ & 29 & Nazaré & 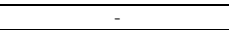 & Círculo vicioso \\
\hline
\end{tabular}




\begin{tabular}{|c|c|c|c|c|c|c|}
\hline $\mathrm{BA}$ & 29 & Nilo Peçanha & Círculo vicioso & Círculo vicioso & Círculo vicioso & - \\
\hline $\mathrm{BA}$ & 29 & Nordestina & Círculo vicioso & Círculo vicioso & Círculo vicioso & Círculo vicioso \\
\hline $\mathrm{BA}$ & 29 & Nova Canaã & Círculo vicioso & Círculo vicioso & - & - \\
\hline $\mathrm{BA}$ & 29 & Nova Fátima & Círculo vicioso & Círculo vicioso & Tendendo ao crescimento & Tendendo ao crescimento \\
\hline $\mathrm{BA}$ & 29 & Nova Ibiá & Círculo vicioso & Círculo vicioso & Tendendo ao crescimento & Tendendo ao crescimento \\
\hline $\mathrm{BA}$ & 29 & Nova Itarana & Círculo vicioso & Círculo vicioso & Círculo vicioso & Círculo vicioso \\
\hline $\mathrm{BA}$ & 29 & Nova Redenção & Círculo vicioso & Círculo vicioso & Círculo vicioso & Círculo vicioso \\
\hline $\mathrm{BA}$ & 29 & Nova Soure & Círculo vicioso & Círculo vicioso & Círculo vicioso & Círculo vicioso \\
\hline $\mathrm{BA}$ & 29 & Nova Viçosa & Círculo vicioso & Tendendo ao crescimento & Tendendo ao crescimento & Círculo virtuoso \\
\hline $\mathrm{BA}$ & 29 & Novo Horizonte & Círculo vicioso & Círculo vicioso & Tendendo ao crescimento & Tendendo ao desenvolvimento \\
\hline $\mathrm{BA}$ & 29 & Novo Triunfo & Círculo vicioso & Círculo vicioso & - & - \\
\hline $\mathrm{BA}$ & 29 & Olindina & Círculo vicioso & - & Tendendo ao crescimento & - \\
\hline $\mathrm{BA}$ & 29 & Oliveira dos Brejinhos & Círculo vicioso & Círculo vicioso & - & Círculo vicioso \\
\hline $\mathrm{BA}$ & 29 & Ouriçangas & Círculo vicioso & Círculo vicioso & Círculo vicioso & Círculo virtuoso \\
\hline $\mathrm{BA}$ & 29 & Ourolândia & Círculo vicioso & Círculo vicioso & Círculo vicioso & Círculo vicioso \\
\hline $\mathrm{BA}$ & 29 & Palmas de Monte Alto & Círculo vicioso & Círculo vicioso & Tendendo ao crescimento & - \\
\hline $\mathrm{BA}$ & 29 & Palmeiras & - & - & Círculo virtuoso & Círculo virtuoso \\
\hline $\mathrm{BA}$ & 29 & Paramirim & Tendendo ao crescimento & Círculo vicioso & Círculo virtuoso & Círculo virtuoso \\
\hline BA & 29 & Paratinga & Círculo vicioso & Círculo vicioso & - & Tendendo ao desenvolvimento \\
\hline $\mathrm{BA}$ & 29 & Paripiranga & Círculo vicioso & Círculo vicioso & Tendendo ao crescimento & Tendendo ao crescimento \\
\hline $\mathrm{BA}$ & 29 & Pau Brasil & Círculo vicioso & Círculo vicioso & Tendendo ao crescimento & Tendendo ao crescimento \\
\hline $\mathrm{BA}$ & 29 & Paulo Afonso & Círculo virtuoso & Tendendo ao crescimento & Círculo virtuoso & Círculo virtuoso \\
\hline $\mathrm{BA}$ & 29 & Pé de Serra & Círculo vicioso & Círculo vicioso & Círculo vicioso & - \\
\hline $\mathrm{BA}$ & 29 & Pedrão & Círculo vicioso & Círculo vicioso & Tendendo ao desenvolvimento & Tendendo ao desenvolvimento \\
\hline $\mathrm{BA}$ & 29 & Pedro Alexandre & Círculo vicioso & Círculo vicioso & Círculo vicioso & - \\
\hline $\mathrm{BA}$ & 29 & Piatã & Círculo vicioso & Círculo vicioso & - & - \\
\hline $\mathrm{BA}$ & 29 & Pilão Arcado & Círculo vicioso & Círculo vicioso & Círculo vicioso & Círculo vicioso \\
\hline $\mathrm{BA}$ & 29 & Pindaí & Círculo vicioso & Círculo vicioso & Tendendo ao desenvolvimento & Círculo virtuoso \\
\hline $\mathrm{BA}$ & 29 & Pindobaçu & Círculo vicioso & Círculo vicioso & Círculo vicioso & - \\
\hline $\mathrm{BA}$ & 29 & Pintadas & Círculo vicioso & Círculo vicioso & Tendendo ao crescimento & Círculo virtuoso \\
\hline $\mathrm{BA}$ & 29 & Piraí do Norte & Círculo vicioso & Círculo vicioso & - & - \\
\hline $\mathrm{BA}$ & 29 & Piripá & Círculo vicioso & Círculo vicioso & - & - \\
\hline $\mathrm{BA}$ & 29 & Piritiba & Círculo vicioso & Círculo vicioso & Tendendo ao crescimento & Tendendo ao crescimento \\
\hline $\mathrm{BA}$ & 29 & Planaltino & Círculo vicioso & Círculo vicioso & Círculo vicioso & Tendendo ao crescimento \\
\hline $\mathrm{BA}$ & 29 & Planalto & Círculo vicioso & Círculo vicioso & Tendendo ao crescimento & Círculo vicioso \\
\hline $\mathrm{BA}$ & 29 & Poções & Círculo vicioso & Círculo vicioso & Tendendo ao crescimento & Tendendo ao crescimento \\
\hline $\mathrm{BA}$ & 29 & Pojuca & - & Tendendo ao crescimento & Círculo virtuoso & Círculo virtuoso \\
\hline $\mathrm{BA}$ & 29 & Ponto Novo & Círculo vicioso & Círculo vicioso & Círculo vicioso & - \\
\hline $\mathrm{BA}$ & 29 & Porto Seguro & Tendendo ao crescimento & Tendendo ao crescimento & Círculo virtuoso & Círculo virtuoso \\
\hline $\mathrm{BA}$ & 29 & Potiraguá & Círculo vicioso & Círculo vicioso & - & Tendendo ao crescimento \\
\hline $\mathrm{BA}$ & 29 & Prado & Círculo vicioso & Círculo vicioso & Tendendo ao crescimento & Círculo virtuoso \\
\hline $\mathrm{BA}$ & 29 & Presidente Dutra & Círculo vicioso & Círculo vicioso & Tendendo ao crescimento & Tendendo ao crescimento \\
\hline $\mathrm{BA}$ & 29 & Presidente Jânio Quadros & Círculo vicioso & Círculo vicioso & - & - \\
\hline $\mathrm{BA}$ & 29 & Presidente Tancredo Neves & Círculo vicioso & Círculo vicioso & Tendendo ao crescimento & Tendendo ao crescimento \\
\hline $\mathrm{BA}$ & 29 & Queimadas & Círculo vicioso & Círculo vicioso & - & Tendendo ao desenvolvimento \\
\hline $\mathrm{BA}$ & 29 & Quijingue & Círculo vicioso & Círculo vicioso & Círculo vicioso & Círculo vicioso \\
\hline $\mathrm{BA}$ & 29 & Quixabeira & Círculo vicioso & Círculo vicioso & - & Círculo vicioso \\
\hline $\mathrm{BA}$ & 29 & Rafael Jambeiro & Círculo vicioso & Círculo vicioso & Círculo vicioso & - \\
\hline $\mathrm{BA}$ & 29 & Remanso & Círculo vicioso & Círculo vicioso & Tendendo ao crescimento & Tendendo ao crescimento \\
\hline $\mathrm{BA}$ & 29 & Retirolândia & Círculo vicioso & - & Tendendo ao crescimento & Círculo virtuoso \\
\hline $\mathrm{BA}$ & 29 & RiachÃo das Neves & Círculo vicioso & Círculo vicioso & Círculo vicioso & - \\
\hline $\mathrm{BA}$ & 29 & RiachÃo do Jacuípe & Círculo vicioso & Círculo vicioso & Tendendo ao crescimento & Círculo virtuoso \\
\hline $\mathrm{BA}$ & 29 & Riacho de Santana & Círculo vicioso & Círculo vicioso & Tendendo ao desenvolvimento & Círculo virtuoso \\
\hline $\mathrm{BA}$ & 29 & Ribeira do Amparo & Círculo vicioso & Círculo vicioso & Círculo vicioso & Círculo vicioso \\
\hline $\mathrm{BA}$ & 29 & Ribeira do Pombal & Círculo vicioso & Círculo vicioso & Tendendo ao crescimento & Tendendo ao crescimento \\
\hline $\mathrm{BA}$ & 29 & Ribeirão do Largo & Círculo vicioso & Círculo vicioso & Círculo vicioso & Tendendo ao crescimento \\
\hline $\mathrm{BA}$ & 29 & Rio de Contas & Círculo vicioso & Círculo vicioso & Círculo virtuoso & Círculo virtuoso \\
\hline $\mathrm{BA}$ & 29 & Rio do Antônio & Círculo vicioso & Círculo vicioso & Círculo vicioso & Círculo vicioso \\
\hline $\mathrm{BA}$ & 29 & Rio do Pires & Círculo vicioso & Círculo vicioso & Tendendo ao crescimento & Círculo vicioso \\
\hline $\mathrm{BA}$ & 29 & Rio Real & Círculo vicioso & Círculo vicioso & Tendendo ao crescimento & Tendendo ao crescimento \\
\hline $\mathrm{BA}$ & 29 & Rodelas & Círculo vicioso & - & Círculo virtuoso & Círculo virtuoso \\
\hline$\frac{\mathrm{BA}}{\mathrm{BA}}$ & 29 & Ruy Barbosa & Círculo vicioso & Círculo vicioso & Círculo virtuoso & Círculo virtuoso \\
\hline $\mathrm{BA}$ & 29 & Salinas da Margarida & - & - & - & Tendendo ao crescimento \\
\hline $\mathrm{BA}$ & 29 & Salvador & Círculo virtuoso & Círculo virtuoso & Círculo virtuoso & Círculo virtuoso \\
\hline $\mathrm{BA}$ & 29 & Santa Bárbara & Círculo vicioso & Círculo vicioso & Círculo vicioso & - \\
\hline $\mathrm{BA}$ & 29 & Santa Brígida & Círculo vicioso & Círculo vicioso & Círculo vicioso & Círculo vicioso \\
\hline $\mathrm{BA}$ & 29 & Santa Cruz Cabrália & Tendendo ao crescimento & - & Círculo virtuoso & Círculo virtuoso \\
\hline $\mathrm{BA}$ & 29 & Santa Cruz da Vitória & Círculo vicioso & Círculo vicioso & - & Círculo virtuoso \\
\hline $\mathrm{BA}$ & 29 & Santa Inês & Círculo vicioso & Círculo vicioso & Círculo virtuoso & Tendendo ao crescimento \\
\hline $\mathrm{BA}$ & 29 & Santaluz & Círculo vicioso & Círculo vicioso & Tendendo ao crescimento & Tendendo ao desenvolvimento \\
\hline $\mathrm{BA}$ & 29 & Santa Luzia & Círculo vicioso & Círculo vicioso & Círculo vicioso & Tendendo ao crescimento \\
\hline $\mathrm{BA}$ & 29 & Santa Maria da Vitória & Círculo vicioso & Círculo vicioso & Círculo virtuoso & Círculo virtuoso \\
\hline $\mathrm{BA}$ & 29 & Santana & Círculo vicioso & Círculo vicioso & Círculo virtuoso & Círculo virtuoso \\
\hline $\mathrm{BA}$ & 29 & Santanópolis & Círculo vicioso & Círculo vicioso & Tendendo ao desenvolvimento & - \\
\hline $\mathrm{BA}$ & 29 & Santa Rita de Cássia & Círculo vicioso & Círculo vicioso & Tendendo ao desenvolvimento & Círculo virtuoso \\
\hline $\mathrm{BA}$ & 29 & Santa Teresinha & Círculo vicioso & - & - & - \\
\hline $\mathrm{BA}$ & 29 & Santo Amaro & - & Círculo vicioso & Tendendo ao crescimento & Círculo virtuoso \\
\hline $\mathrm{BA}$ & 29 & Santo Antônio de Jesus & Círculo virtuoso & Círculo virtuoso & Círculo virtuoso & Círculo virtuoso \\
\hline $\mathrm{BA}$ & 29 & Santo Estêvão & Círculo vicioso & - & Tendendo ao crescimento & Círculo virtuoso \\
\hline $\mathrm{BA}$ & 29 & São Desidério & Círculo vicioso & Círculo vicioso & Tendendo ao crescimento & Tendendo ao crescimento \\
\hline $\mathrm{BA}$ & 29 & São Domingos & Círculo vicioso & - & Tendendo ao crescimento & Círculo virtuoso \\
\hline $\mathrm{BA}$ & 29 & São Félix & Círculo vicioso & - & Tendendo ao crescimento & Círculo virtuoso \\
\hline BA & 29 & São Félix do Coribe & Círculo vicioso & Círculo vicioso & Círculo virtuoso & Círculo virtuoso \\
\hline $\mathrm{BA}$ & 29 & São Felipe & Círculo vicioso & Círculo vicioso & Círculo virtuoso & Círculo virtuoso \\
\hline BA & 29 & $\begin{array}{l}\text { São Francisco do } \\
\text { Conde }\end{array}$ & 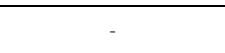 & $\begin{array}{c}\text { Tendendo ao } \\
\text { desenvolvimento }\end{array}$ & Círculo virtuoso & Círculo virtuoso \\
\hline $\mathrm{BA}$ & 29 & São Gabriel & Círculo vicioso & Círculo vicioso & Tendendo ao crescimento & - \\
\hline BA & 29 & $\begin{array}{l}\text { São Gonçalo dos } \\
\text { Campos }\end{array}$ & Círculo vicioso & Círculo vicioso & Tendendo ao crescimento & Tendendo ao crescimento \\
\hline $\mathrm{BA}$ & 29 & São José da Vitória & Círculo vicioso & Círculo vicioso & Círculo vicioso & Círculo vicioso \\
\hline $\mathrm{BA}$ & 29 & São José do Jacuípe & Círculo vicioso & Círculo vicioso & Círculo vicioso & Círculo vicioso \\
\hline $\mathrm{BA}$ & 29 & São Miguel das Matas & Círculo vicioso & Círculo vicioso & Tendendo ao crescimento & Tendendo ao crescimento \\
\hline $\mathrm{BA}$ & 29 & São Sebastião do Passé & Círculo vicioso & - & Círculo virtuoso & Círculo virtuoso \\
\hline $\mathrm{BA}$ & 29 & Sapeaçu & Círculo vicioso & Círculo vicioso & Círculo virtuoso & Tendendo ao crescimento \\
\hline
\end{tabular}




\begin{tabular}{|c|c|c|c|c|c|c|}
\hline $\mathrm{BA}$ & 29 & Sátiro Dias & Círculo vicioso & Círculo vicioso & Círculo vicioso & Círculo vicioso \\
\hline $\mathrm{BA}$ & 29 & Saubara & - & - & Tendendo ao crescimento & Tendendo ao crescimento \\
\hline $\mathrm{BA}$ & 29 & Saúde & Círculo vicioso & Círculo vicioso & - & Círculo vicioso \\
\hline $\mathrm{BA}$ & 29 & Seabra & Círculo vicioso & - & Tendendo ao crescimento & $\begin{array}{l}\text { Círculo virtuoso } \\
\end{array}$ \\
\hline $\mathrm{BA}$ & 29 & Sebastião Laranjeiras & Círculo vicioso & Círculo vicioso & Círculo virtuoso & Círculo virtuoso \\
\hline $\mathrm{BA}$ & 29 & Senhor do Bonfim & Tendendo ao crescimento & - & Tendendo ao crescimento & Círculo virtuoso \\
\hline $\mathrm{BA}$ & 29 & Serra do Ramalho & Círculo vicioso & Círculo vicioso & - & Tendendo ao desenvolvimento \\
\hline $\mathrm{BA}$ & 29 & Sento Sé & Círculo vicioso & Círculo vicioso & Círculo vicioso & - \\
\hline $\mathrm{BA}$ & 29 & Serra Dourada & Círculo vicioso & Círculo vicioso & Tendendo ao desenvolvimento & Tendendo ao desenvolvimento \\
\hline $\mathrm{BA}$ & 29 & Serra Preta & Círculo vicioso & Círculo vicioso & Círculo vicioso & $\begin{array}{c}\text { Círculo vicioso } \\
\end{array}$ \\
\hline $\mathrm{BA}$ & 29 & $\begin{array}{l}\text { Serrinha } \\
\end{array}$ & Círculo vicioso & Círculo vicioso & $\begin{array}{l}\text { Círculo virtuoso } \\
\end{array}$ & $\begin{array}{l}\text { Círculo virtuoso } \\
\end{array}$ \\
\hline $\mathrm{BA}$ & 29 & Serrolândia & Círculo vicioso & Círculo vicioso & Círculo virtuoso & - \\
\hline $\mathrm{BA}$ & 29 & Simões Filho & Tendendo ao crescimento & $\begin{array}{c}\text { Tendendo ao } \\
\text { desenvolvimento }\end{array}$ & Círculo virtuoso & Círculo virtuoso \\
\hline $\mathrm{BA}$ & 29 & $\begin{array}{l}\text { Sítio do Mato } \\
\end{array}$ & Círculo vicioso & $\begin{array}{l}\text { Círculo vicioso } \\
\end{array}$ & Círculo vicioso & Tendendo ao desenvolvimento \\
\hline $\mathrm{BA}$ & 29 & Sítio do Quinto & Círculo vicioso & Círculo vicioso & Tendendo ao crescimento & Círculo vicioso \\
\hline $\mathrm{BA}$ & 29 & Sobradinho & - & Círculo vicioso & Tendendo ao crescimento & Tendendo ao crescimento \\
\hline $\mathrm{BA}$ & 29 & $\begin{array}{l}\text { Souto Soares } \\
\end{array}$ & Círculo vicioso & Círculo vicioso & Círculo vicioso & - \\
\hline $\mathrm{BA}$ & 29 & Tabocas do Brejo Velho & Círculo vicioso & Círculo vicioso & Tendendo ao desenvolvimento & Tendendo ao desenvolvimento \\
\hline $\mathrm{BA}$ & 29 & Tanhaçu & Círculo vicioso & Círculo vicioso & Tendendo ao crescimento & Tendendo ao crescimento \\
\hline $\mathrm{BA}$ & 29 & Tanque Novo & Círculo vicioso & Círculo vicioso & - & Tendendo ao crescimento \\
\hline $\mathrm{BA}$ & 29 & Tanquinho & Círculo vicioso & Círculo vicioso & Tendendo ao crescimento & Tendendo ao crescimento \\
\hline $\mathrm{BA}$ & 29 & Taperoá & Círculo vicioso & Círculo vicioso & Círculo vicioso & Tendendo ao crescimento \\
\hline $\mathrm{BA}$ & 29 & Tapiramutá & Círculo vicioso & Círculo vicioso & Tendendo ao crescimento & Tendendo ao crescimento \\
\hline $\mathrm{BA}$ & 29 & Teixeira de Freitas & Tendendo ao crescimento & Tendendo ao crescimento & Círculo virtuoso & Círculo virtuoso \\
\hline $\mathrm{BA}$ & 29 & Teodoro Sampaio & Círculo vicioso & Círculo vicioso & Círculo virtuoso & Tendendo ao crescimento \\
\hline $\mathrm{BA}$ & 29 & Teofilândia & Círculo vicioso & Círculo vicioso & Tendendo ao crescimento & Tendendo ao crescimento \\
\hline $\mathrm{BA}$ & 29 & Teolândia & Círculo vicioso & Círculo vicioso & - & - \\
\hline $\mathrm{BA}$ & 29 & Terra Nova & Círculo vicioso & Círculo vicioso & Círculo virtuoso & Tendendo ao crescimento \\
\hline $\mathrm{BA}$ & 29 & Tremedal & Círculo vicioso & Círculo vicioso & - & Círculo vicioso \\
\hline $\mathrm{BA}$ & 29 & Tucano & Círculo vicioso & Círculo vicioso & Círculo vicioso & Tendendo ao crescimento \\
\hline $\mathrm{BA}$ & 29 & Uauá & Círculo vicioso & Círculo vicioso & - & - \\
\hline $\mathrm{BA}$ & 29 & Ubaíra & Círculo vicioso & Círculo vicioso & Tendendo ao crescimento & Tendendo ao crescimento \\
\hline $\mathrm{BA}$ & 29 & Ubaitaba & Círculo vicioso & Círculo vicioso & Tendendo ao crescimento & Círculo virtuoso \\
\hline $\mathrm{BA}$ & 29 & Ubatã & Círculo vicioso & Círculo vicioso & Tendendo ao crescimento & Tendendo ao crescimento \\
\hline $\mathrm{BA}$ & 29 & $\begin{array}{l}\text { Uibaí } \\
\end{array}$ & Círculo vicioso & Círculo vicioso & Tendendo ao crescimento & Círculo virtuoso \\
\hline $\mathrm{BA}$ & 29 & Umburanas & Círculo vicioso & Círculo vicioso & Círculo vicioso & $\begin{array}{l}\text { Círculo vicioso } \\
\end{array}$ \\
\hline $\mathrm{BA}$ & 29 & Una & Círculo vicioso & Círculo vicioso & Tendendo ao crescimento & Tendendo ao crescimento \\
\hline $\mathrm{BA}$ & 29 & Urandi & Círculo vicioso & Círculo vicioso & Círculo virtuoso & Tendendo ao crescimento \\
\hline $\mathrm{BA}$ & 29 & Uruçuca & Círculo vicioso & Círculo vicioso & Tendendo ao crescimento & Círculo virtuoso \\
\hline $\mathrm{BA}$ & 29 & $\begin{array}{l}\text { Utinga } \\
\end{array}$ & Círculo vicioso & Círculo vicioso & Círculo vicioso & Tendendo ao crescimento \\
\hline $\mathrm{BA}$ & 29 & Valença & Círculo vicioso & Círculo vicioso & Círculo virtuoso & Círculo virtuoso \\
\hline $\mathrm{BA}$ & 29 & $\begin{array}{l}\text { Valente } \\
\end{array}$ & Círculo vicioso & - & Círculo virtuoso & Tendendo ao crescimento \\
\hline $\mathrm{BA}$ & 29 & Várzea da Roça & Círculo vicioso & Círculo vicioso & $\begin{array}{l}\text { Círculo vicioso } \\
\end{array}$ & - \\
\hline $\mathrm{BA}$ & 29 & Várzea do Poço & Círculo vicioso & Círculo vicioso & Círculo virtuoso & Tendendo ao crescimento \\
\hline $\mathrm{BA}$ & 29 & Várzea Nova & Círculo vicioso & Círculo vicioso & Círculo vicioso & $\begin{array}{l}\text { Círculo vicioso } \\
\end{array}$ \\
\hline $\mathrm{BA}$ & 29 & Varzedo & $\begin{array}{l}\text { Círculo vicioso } \\
\end{array}$ & Círculo vicioso & - & Tendendo ao cres cimento \\
\hline $\mathrm{BA}$ & 29 & $\begin{array}{l}\text { Vera Cruz } \\
\end{array}$ & Tendendo ao crescimento & - & Círculo virtuoso & Círculo virtuoso \\
\hline $\mathrm{BA}$ & 29 & Vereda & Círculo vicioso & Círculo vicioso & Tendendo ao crescimento & Tendendo ao crescimento \\
\hline $\mathrm{BA}$ & 29 & Vitória da Conquista & Tendendo ao crescimento & Tendendo ao crescimento & Círculo virtuoso & Círculo virtuoso \\
\hline $\mathrm{BA}$ & 29 & Wagner & Círculo vicioso & Círculo vicioso & Tendendo ao crescimento & Tendendo ao crescimento \\
\hline $\mathrm{BA}$ & 29 & $\begin{array}{l}\text { Wanderley } \\
\end{array}$ & Círculo vicioso & Círculo vicioso & Tendendo ao crescimento & Círculo virtuoso \\
\hline $\mathrm{BA}$ & 29 & Wenceslau Guimarães & Círculo vicioso & Círculo vicioso & - & $\begin{array}{l}\text { Círculo vicioso } \\
\end{array}$ \\
\hline $\mathrm{BA}$ & 29 & Xique-Xique & Círculo vicioso & Círculo vicioso & - & Tendendo ao crescimento \\
\hline
\end{tabular}

Fonte: Elaboração própria a partir dos dados do Pnud (2016). 
Endereço para correspondência:

Nadja Simone Menezes Nery de Oliveira - nadja.menezes@correounivalle.edu.co Calle 13 \# 100-00 Ciudad Universitaria Meléndez

Edificio D12, Código Postal 76001

Cali, Valle del Cauca, Colombia

Jandir Ferrera de Lima - jandirbr@yahoo.ca

Rua da Faculdade, 645, Jardim Santa Maria 85.903-000 Toledo/PR, Brasil

Roselaine Navarro Barrinha - roselainenbs@gmail.com

Rua da Faculdade, 645, Jardim Santa Maria

85.903-000 Toledo/PR, Brasil 